Research report

\title{
Patterns of children's travel to school, their body weight, spatial factors, and perceptions: A survey on nine European cities
}

Houshmand E. Masoumi ${ }^{1 *}$ - Gabriele Zanoli ${ }^{2}$ - Athanasios Papageorgiou ${ }^{3}$

- Soultana Smaga ${ }^{3}$ - Ana Miloš ${ }^{4}$ - Martin van Rooijen ${ }^{5}$ - Monika Łuczak $^{6}$

- Joanna Komorek ${ }^{6}$ - Birol Çağan ${ }^{7}$

${ }^{1}$ Center for Technology and Society, Technische Universität Berlin, Germany.

Corresponding author. Email: masoumi@ztg.tu-berlin.de

${ }^{2}$ Centro Sportivo Italiano, Italy.

${ }^{3}$ The Northern Greece Physical Education Teachers' Association, Greece.

${ }^{4}$ Rijeka Sports Association for Persons with Disability, Croatia.

${ }^{5}$ Harten voor Sport, The Netherlands.

${ }^{6}$ Wyzsza Szkola Biznesu i Nauk o Zdrowiu, Poland.

${ }^{7}$ Dogansehir Genclik Hizmetleri Ve Spor Ilce Mudurlugu, Turkey.

Abstract: Increasing rates of body weight of children has become a motivation for investigating active transportation to school during the past years. Lack of proper data covering different geographical contexts is a problem seen in the literature of this subject. The present paper reports the findings of a recent survey on nine cities in seven European countries funded by the European Commission. The objective of the survey was to provide data covering several topics in relation with active commuting to school and body mass index, such as parental perceptions of safety and security, neighborhood facilities, land use characteristics, etc. in different regions of Europe in a way that cross-sectional comparisons between regions and city sizes is facilitated. For that, 2735 children/parents were handed out questionnaires, from whom 1424 filled out the questionnaires (response rate: $52 \%$ ). This led to 1304 validated questionnaires. The respondents studied in 21 elementary schools of Foggia, Italy; Berlin, Germany; Thessaloniki, Greece; Rijeka, Croatia; Utrecht, The Netherlands; Łódź, Poland; Konstantynow, Poland; Malatya, Turkey, and Doğanşehir, Turkey as of March 2016 until January 2017. The survey instrument enables development of continuous and categorical variables for empirical research with strong focus on the built environment using the aggregate data provided by this study. It is expected that the output data eases production of knowledge about less-studied European contexts as well as cross-sectional comparison of results with more studied areas of Western Europe.

Key words: Active transport to school, children's body weight, urban form, perceived built environment

Highlights for public administration, management and planning:

- The survey is done on nine cities in seven European countries located in different regions.

- 2735 questionnaires were handed out, 1424 of which were filled out; 1304 were validated, providing response rate of $52.07 \%$.

- The preliminary and descriptive analysis of data shows cultural and geographical differences in mobility patterns of children, the perceptions, and the body weights.

Received: 14 Aug 2017 - Received in revised form: 6 Nov 2017 - Accepted: 13 Nov 2017 


\section{Introduction}

This research report summarizes the results of a survey on the topic of active transport to school, the built environment characteristics, the perceptions of parents and children, and finally children's body weight in the European context. The survey was conducted from March 2016 until January 2017 in nine European cities. The necessity of conducting this survey lies in the knowledge gaps identified in the European studies (Masoumi 2017), including (1) associations between the perceptions and mobility behaviors of parents and children concerning barriers of Active Transport to School (ATS), (2) additional research on the associations of ATSBody Mass Index (BMI) to add to the consistency of international results, (3) contextual studies on the ATS-BMI topic with adding the less-studied contexts to the European studies, (4) studies on the behaviors of children without bringing in the adolescents or vice versa, (5) integration of built environment variables in ATS-BMI studies.

The overall objective of this survey is to collect data and information about the patterns of school travels of 9-12-year-old children, the outdoor-activity-related perceptions of children and their parents, as well as the children's body weight in the European context. It meant to provide data covering several topics in relation with active commuting to school and body mass index, such as parental perceptions of safety and security, neighborhood facilities, land use characterristics, etc. in different regions of Europe in a way that cross-sectional comparisons between regions and city sizes is facilitated. The structure of the survey instrument facilitates comparisons between cities and regions located in far-away locations throughout Europe. This survey was designed to address some of the identified knowledge gaps identified (Masoumi 2017), including (1) providing subjective data in order to examine the attitudes and perceptions of both children and their parents concerning safety, security, and mobility; (2) providing data for mathematical analyses and models that can confirm or reject the correlations between ATS and BMI so that consistency of overall results is increased by confirming the results of one of the two sides; (3) collecting data about less-studied European countries like Croatia, Poland, Greece, and Turkey, as well as relatively studied contexts such as Germany, Netherlands, and Italy, so that conditions of comparison is established; (4) collecting data focusing only on children; (5) providing data by means of secondary data and map work about built environment so that the correlations between urban form, ATS, and BMI are more thoroughly investigated.

This paper continues with a methodological review of the European and international surveys on the relevant topics. Then the technical aspects of the survey methodology are presented in a way that other researchers can make use of them or can reproduce them. The findings are illustrated in a collective way by means of tables, and finally the findings are discussed with special regards to the knowledge gaps addressed in this manuscript.

\section{Similar Previous Surveys}

The following surveys have been conducted with the aim of providing data for studying children's mobility patterns and their body weight in different contexts. Comparable previous surveys have been done in several countries, most of which are industrial high-income ones. The examples are briefly explained here. In order to study the parental perceptions traffic dangers of children's mobility to school and the effects of the built environment, Rothman et al. (2015) undertook a self-administered survey gathering the data of 733 pupils of 20 elementary school in Toronto, Canada. Their main aim was to examine the associations between frequent walking to school for 4 to 5 times per week and parents' perceptions of traffic risk, as well as correlations between what parents perceive about high levels of school route traffic danger and social and built environment characteristics. The response rate of this study was $38 \%$. With the aim of finding associations of ATS and children's obesity, another Canadian study was done on 315 pupils of both sexes in grades 4 to 6 in Eastern Ontario applying self-reported questionnaires, while the measurements were done by the research team using a portable stadiometer (Larouche et al. 2011). Before that, a larger survey had been done in Quebec with the same data collection app- 
roach on 1170 children in kindergarten to grade 2 with both sexes (Pabayo et al. 2010). The data collection of this study was undertaken in 1997 and 1998 leading to publication of longitudinal results in 2010. This study meant to find the correlations of active school commuting with changes in BMI in children with 6 to 8 years of age.

The surveys done in the USA have a larger share, exemplified by four studies in this paper: Rosenberg et al. (2006) studied the 924 children with both sexes in 5th grade in seven suburban elementary schools in California back in 19901992 to find potential benefits of active school transport on measures of weight status and physical activity. Heelan et al. (2005) collected the data of 320 boys and girls in eight rural schools in Nebraska to find out if active commuting provides sufficient physical activity to affect BMI, and if it contributes to attainment of physical activity recommendations. In this study, the questionnaires were sent to students' houses, while the body measurements were done by the research staff. In 2005, Fulton et al. published the results of their study on 1458 children/youngsters in grades 4 to 12 based on a nation-wide survey done in 1996 by random digit-dial household survey and computer-assisted telephone interviews. A more recent study was conducted by Mendoza et al. (2014) based on longitudinal data collections in 1998-2004 on 12022 children. In order to explore the associations of active transport to and from kindergarten with fifthgrade adiposity, the body measurements were done by staff using Shorr board and Seca digital scale

European countries have also their share. The example of these studies have been done in Sweden (Chillón et al. 2012) in 1998-2005, who collected the longitudinal data of 262 children of both sexes aged 9 to 15 using computerized selfreported questionnaires, as well as a newer study done in Norway based on the data collected in 2005-2006 from 2299 children of 9 to 15 years of age in 40 elementary schools and 23 high schools (Ostergaard et al. 2013). The Swedish study aimed to test whether modes of commuting to school and changes in commuting were associated with 6-year changes in youth, while the
Norwegian one targeted correlations between body composition, cardiorespiratory and muscular fitness with school trip modes in children and adolescents. In 2007, data about walking and cycling habits of 2012 children including 899 boys and 1113 girls in Norfolk, UK, as well as the built environment around children's homes were collected. GIS were applied to quantify the urban form and distances to schools around homes, while the school environments were assessed by an audit developed especially for the research (Panter et al. 2010). This study aimed to find objective relations between characteristics of the neighborhood, route, and school environments on the one side and active transport to school among children. The Spanish situation was examined by a study published in 2015 (Gutiérrez-Zornoza et al.) based on the survey done in 2006 in Cuenca, Spain, collecting data about 956 children including 472 boys and 484 girls studying in 18 public schools in rural areas for cross-sectional study. This data collection was undertaken to investigate the role of distance to school as well as associations of ATS and children's health.

Such surveys have not been limited to the highincome countries. A limited number of data collection activities have also been executed in some of the developing and emerging countries, two of which are briefly explained below. In order to examine associations of parental psychological and socio-economic factors and the built environment with primary school children's school trip mode choice in Rasht, Iran, and the connections with land use and psychological issues, Mehdizadeh et al. (2016) conducted a survey on pupils of nine primary public and private schools in 2014. With a response rate of $80 \%, 735$ questionnaires were filled out. An example of the Chinese surveys is the work done by Sun et al. (2015), who did a large data collection on 21596 children and adolescents (9445 boys and 12151 girls) of 1st to 12th grades in eight cities of China, of whom 21280 students had Body Mass Index information. This survey was done in 2010 to investigate school travel mode choices and associations with physical and mental well-being among Chinese children. There are also studies covering more than one country, such as the work done by Sarmiento et al. (2015) 
on 6797 students of 9 to 11 years of both sexes in 15 cities located in Australia, Brazil, Canada, China, Colombia, Finland, India, Kenya, Portugal, South Africa, UK, and USA, that was done to find the possible associations between Body Mass Index z-score, obesity, percentage body fat, waist circumference with active commuting to school. A summary of the main characteristics of the data collections explained in this section can be found in Table 1).

\section{Methodology}

The structure of the survey and the findings are in a way that it enables researchers to do crosssectional studies using both continuous and dichotomous variables. Hence, using the findings several statistical analysis methods including regression and discrete choice models may be applied. The geographical distribution of casestudy cities in Europe are in a way that it can provide a good coverage to most parts of the continent. Less represented areas are Scandinavia, British Isles, Iberian Peninsula, and the Commonwealth of Independent States. Moreover, the questions were formulated by in-depth review of the existing literature, so the responses are considered to be able to provide answers to a wide range of issues regarding the built environment, mobility, and the body characteristics. The findings are divided into two groups of the direct findings of the survey, and the data provided based on the urban form of the surrounding of the schools. The former group of findings are disaggregated data, while the latter are aggregate based on the $3^{*} 3 \mathrm{~km}$ rectangular catchment areas around the schools.

This survey was conducted with the assumption that samples with subjects more than 1000 can provide better power. The sample size of the study $(\mathrm{N}=1304)$ was more than a number of similar studies (i.e. Rosenberg et al. 2006; Yeung et al. 2008; Pabayo et al. 2010; Larouche et al. 2011; Chillón et al. 2012; Gutiérrez-Zornoza et al. 2015; Rothman et al. 2015; Mehdizadeh et al. 2016). Thus, it is expected that better inclusiveness of data can be provided by a larger sample. This is a finding of a recent systematic review of English-language journal paper published between 2005 and 2015 with the topic of active transport to school and children's body weight (Masoumi 2017).

The eight survey cities examined in this survey were Foggia, Italy; Berlin, Germany; Thessaloniki, Greece; Rijeka, Croatia; Utrecht, The Netherlands; Łódź, Poland; Konstantynow, Poland; Malatya, Turkey, and Doğanşehir, Turkey. Table 2 summarizes the case-study information regarding population and city size. For the above city size categorization, the classification of (Dühr 2005) is applied: cities with population of more than 1000000 are major cities, cities with between 500000 and one million inhabitants as large cities, those with between 250000 and 500000 inhabitants as small cities, and finally areas with less than 250000 residents as micro cities.

Like land use, locations of schools in districts with very different socio-cultural and economic status and background was intended so that a better variability of factors related to socio-economics, namely household average monthly income and costs, were extracted. High levels of socioeconomic variability were intended for better statistical modeling. The schools were selected from the elementary schools so that the intended ages of 9 to 12 were reached. The obligation of having this age limitation in this study was because this research was a part a larger project with the aim of designing practice methods and research and development tools for training and sport practicing as well as promotion of the physical activity of children in European cities.

The survey instrument was a self-reported questionnaire that collected raw data about children's body measurements and the mobility habits of children and their parents as well as their perceptions toward safety and security. 26 questions were designed in a two-page questionnaire. The parents were the main respondents. They were asked to fill out the questionnaires with presence of their children in school or at home. The questions were embedded in four sections: individual/household information, parent's travel habits, travel to school, and finally perceptions of the school travel routes. Most of the questions were formulated for collecting qualitative data in form of categorical divisions. 


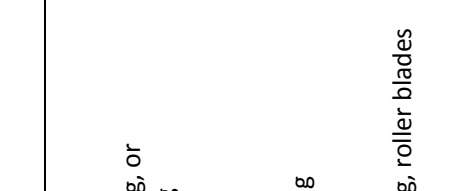

III

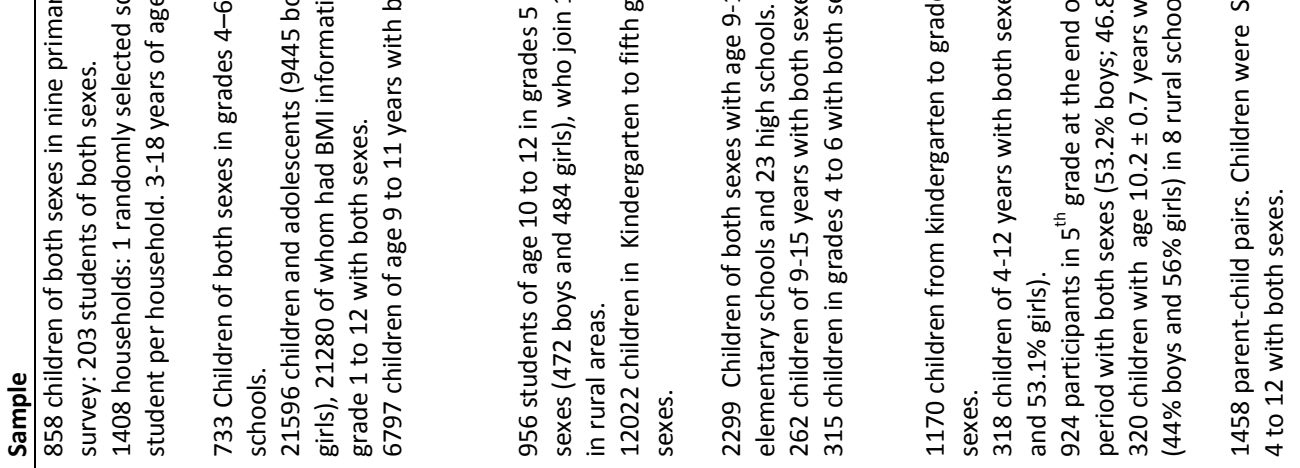

in

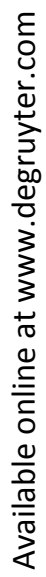

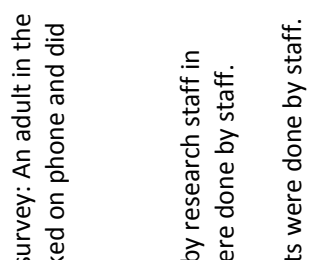

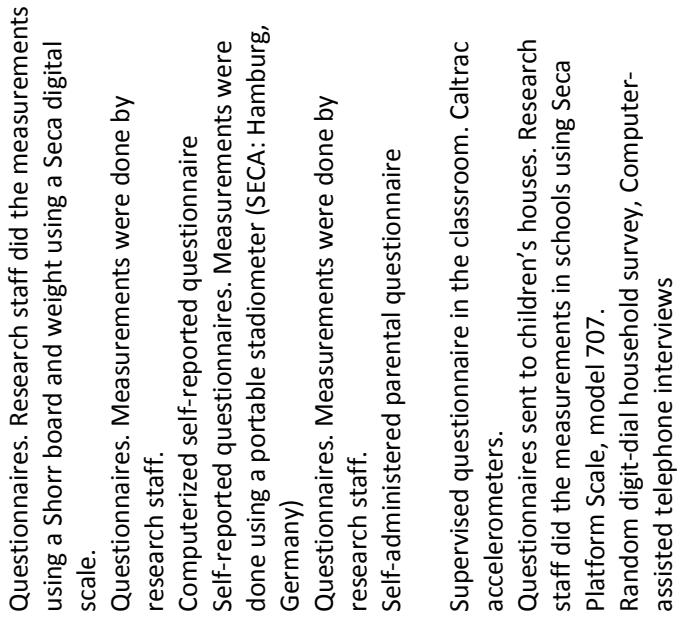

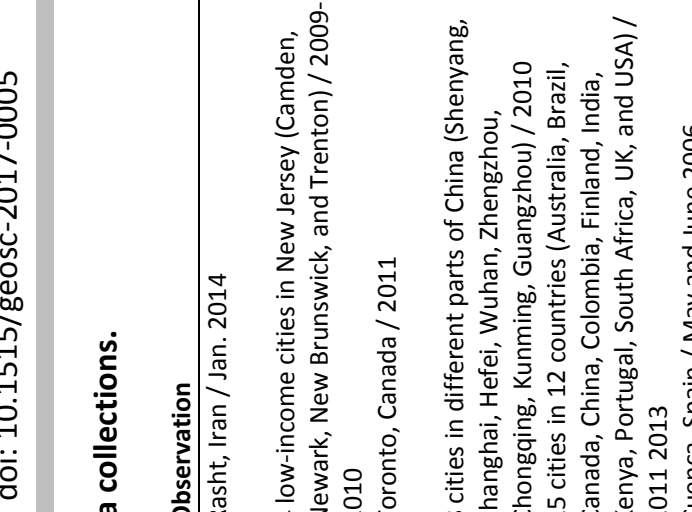

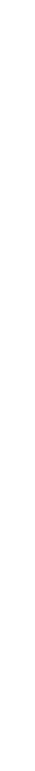

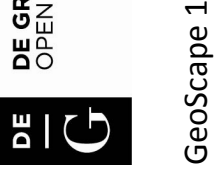

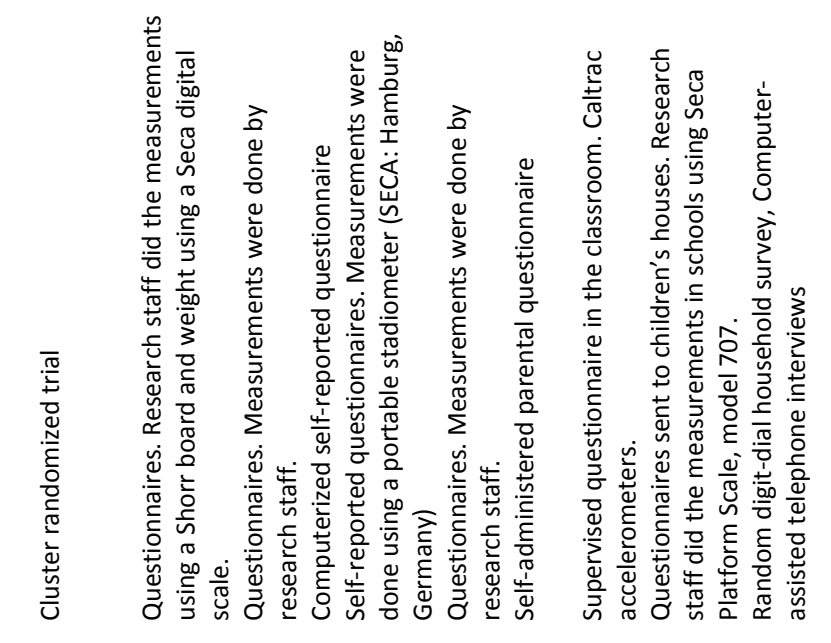


Table 2 - The nine European cities selected for survey.

\begin{tabular}{ccccr} 
No. & Case-Study City & $\begin{array}{l}\text { City } \\
\text { Size }\end{array}$ & $\begin{array}{l}\text { Coun } \\
\text { try }\end{array}$ & $\begin{array}{l}\text { Popul. } \\
\text { (Thous. } \\
\text { Inhab.) }\end{array}$ \\
\hline 1 & Foggia & Micro & IT & 153 \\
2 & Berlin & Major & DE & 3500 \\
3 & Thessaloniki & Large & GR & 824 \\
4 & Rijeka & Small & HR & 213 \\
5 & Utrecht & Small & NL & 330 \\
6 & tódź & Major & PL & 1000 \\
7 & Konstantynow & Mirco & PL & 17 \\
8 & Malatya & Large & TR & 770 \\
9 & Doğanşehir & Micro & TR & 41
\end{tabular}

The selected schools were samples of populations as small as 567 nine-to-twelve-year-old children in Konstantynow, Poland to a large population of 110918 children in Berlin (Supplement 1). The data of children in 21 schools were collected, in a way that they were located in different urban structures in a certain city. Different urban fabrics such as compact urban forms in the central cities, lower-density suburban areas, different street network configurations like complete or semi-complete grids, housing characteristics like high-rise buildings, detached or semi-detached houses, etc. were the basis of providing diversity and variability of land uses.

The survey instrument was not exactly similar to any of the studies addressed in the background, methodology, and discussion sections of this paper, but it was attempted to highlight to most important aspects of the issues related to the topic of active school commuting and body weight. Supplement 2 illustrates the questionnaire in English. The questionnaire was structured primarily in English and was translated to local languages.

Four large variable categories were employed to accommodate different factors. These factors were selected based on literature review and identification of knowledge gaps. The variables were designed in a way that the main factors in previous studies were repeated and also some less studied phenomena like perceptions and spatial issues were integrated into the question- naire. It was also tried to keep the survey instrument as brief as possible. Below the variables and their categories are explained. The variables were designed to explore new insights to the urban form characteristics around schools and the body mass index of children in different contexts, the inter-relations of the perceptions of travel behaviors of children and parents, the differences between the levels of active commuting to school in different European contexts, and the necessary or useful intervenetions in the built environment for promotion of active transport to school. However, some variables were designed to answer smaller pieces of questions.

\section{Demographic and socio-economic variables}

The source of these data is the questionnaire. These variables are related to the characteristics of children and their family status. Their age has been $9,10,11$, or 12 . The gender was assumed to be male or female. The financial indicators are the variables that were the most difficult data to collect from families. If only household income would be taken as a variable, then the real purchase power would not be indicated in the analyses. Socio-demographic factors (Cao et al. 2009; Soltanzadeh \& Masoumi 2014) as well as economic issues (Heinen \& Chatterjee 2015; Roque \& Masoumi 2016) may be determinants of mobility decision and habits of adults. With the possible connections between the mobility decisions of adults and their children as well as between children's mobility and their health, it can be expected that socioeconomics and demographics may be of importance for studying pupils' mobility and body weight. The target variables of this group were age, gender, weight and height (accordingly obesity, overweight, and BMI), household size, number of children, household members working, and household costs/income ratio.

\section{Travel variables}

The source of these data is the questionnaire. The first part of these variables is related to parent's travels. Five Variables were related to commuting habits of both parents and children. 
Car ownership and household members holding a driving license are basically continuous but it was possible to make them categorical where necessary. The other four variables are categorical from the beginning. The questions of this part were design to develop variables about car ownership, driving license ownership, father's mode choice, mother's mode choice, shopping in neighbourhood, and entertainment in neighbourhood. For simplification of data collection about families, it was assumed that children have fathers and mothers. Those children that had mother and mother or father and father, could give the travel information of one of them. This was also the case for children with only one living parent. The second series of variables related to travels are variables of travel to school. The variables related to school travel are categorical except two of them: the distance between from the nearest intersection to home and school, which is continuous at the first step, but can be changed to dichotomous variable later. One of the most desirable potential variables targets persons who accompany the student to school. In the last option of this question, "siblings" are put together with "close relatives", which means grandparents and uncles/aunts, as well as "others", which refers to those who may help the family take their children to school such as family friends, neighbors, and family helpers like nannies and housekeepers. The second question providing continuous data sought the number of crossings between home and school. This refers to crossing streets of all types and targets objective measures of road safety. Variables about Distance of travel to school, school travel mode choice, accompanying the child to school, child bike ownership, and number of crossings between home and school were sought.

\section{Perceptions of the school travels}

The source of these data is the questionnaire. Categorical data regarding perceptions of both parents and children applying five-point Likert scale were collected as a part of this section. Complementary information about the meaning "safety" and "security" are given to surveyors and respondents in survey guidelines, though in several languages there is only one word for these two meanings. The research team in all countries were in contact with the school authorities and sometimes directly with parents, so if the teachers and authorities or the parents had questions, the team gave further explanations. The goal was that during the preliminary negotiations with schools, enough description of the goals and methods of the survey were provided for them so that they can better transfer them to parents. It was attempted that the explanations of research staff can clarify the issue for the respondents. The parents were set free to fill out the questionnaires at school or at home, but they were asked to fill them out together with children, since two of the questions targeted the perceptions and feelings of the children. The data of this section were meant to be used for variables about student safety perception, student security perception, family safety perception, family security perception, perception of quality of sidewalks, and perception of quality of bike routes.

\section{Spatial variables}

The development methods of some of the variables in this group are mainly similar to those applied by (Sallis et al. 2016) (connectivity, accessibility to public transportation, population density, and neighborhood green space). In order to quantify urban form variables, computerbased work like Geographic Information Systems (GIS) were not used. Instead, these quantifications were conducted manually using the secondary statistics, the sources of which are presented in Supplement 1, as well as the online maps like Google Maps. The bases of estimations are catchment areas made by $3 * 3 \mathrm{~km}^{2}$ rectangles centered by each school. Since ATS is includes not only walking but also bicycling, pedestrian sheds of 800 meters or similar measures were not applied $^{1}$. Instead, larger areas were taken so that bicycle travels from home to school can also be investigated. For simplifying the calculations by all partners, rectangles were taken instead of the conventional circular catchment areas. Rectangles of nine $\mathrm{km}^{2}$ were employed to calculate the urban form variables. In cases that the school were located on the edge of the city, the city was so small that a part of the catchment area 
remained unbuilt, or there were a water body like see, river, etc., the unbuilt area was distracted from the nine $\mathrm{km}^{2}$. Thus, in some cases the catchment area was less than nine $\mathrm{km}^{2}$ and the urban form variables have been proportionally changed. Open/green spaces are small or large open neighborhood spaces, in which children can play or pass time together with or without parents. Such spaces can in some cases be very small pieces of land like small playgrounds. City size is one of the factors examined in this study. The last variable is the population of the pilot cities, in which the schools are located. The populations may be related to different years, but all of them are from the recent three or four years. The connectivity of street networks was calculated by dividing the number of all types of intersections (primary, secondary, etc.) intersections in the school neighborhood by the area. Accessibility to public transportation was estimated by dividing the number of public transport stations (bus, rail, etc.) by population multiplied by 1000 . Population density was calculated by dividing the population in the catchment area centered by the school by area in hectare (in most of the cases: $9 \mathrm{~km}^{2}$ ). Neighborhood open/green space was estimated by counting the number of public spaces like urban parks or other spaces in the school neighborhood/district. Finally, the city size was presented by the raw population data derived from census data of the partner countries.

The survey has been conducted as an exploratory approach to the topic of ATS and children's body weight. Nevertheless, it would be interesting to have an understanding about the levels of representativeness of the data collection. For estimating the representativeness of this survey, availability of the statistics related to the population of comparable children with the same age class in the pilot cities was a key figure. Collecting this data was difficult in most of the study cities. Hence, in some cases a rough estimation of the population of 9 to 12-year children has been provided by our research team. Supplement 1 shows these figures with further descriptions regarding the method of estimation in cases that the exact populations were not available.
This study takes the formulation developed by (Cochran 1963, 75) for the purpose of examining sample size. There are two formulations for this aim:

$$
n_{0}=\frac{Z^{2} p q}{e^{2}}
$$

Whereas $Z^{2}$ is the abscissa of the normal curve, $p$ is the estimated proportion of an attribute, e is the level of precision, and finally $q$ is equal to 1-p. The result is adjusted by the following relation

$$
n=\frac{n_{0}}{1+\frac{\left(n_{0}-1\right)}{N}}
$$

Whereas $n$ is the sample size (number of valid filled questionnaires shown in Suppl. 6).

In Supplement 1, the value of e is shown based on the sample sizes in different cities, where $\mathrm{N}$ is the population of children with 9 to 12 years of age presented in the fourth column of the table. In calculation of sample rations, the confidence level has been $95 \%$. Concerning representativeness, it should be mentioned that the ratios, precisions, and in general representativeness written in Supplement 1 refers only to the cities not the countries. Small data collections in three schools cannot be a good representative of a country. However, the levels of representativeness can be estimated by the precisions, e.g. the descriptive statistics found for the city of Rijeka, Croatia, can be $6.69 \%$ more or less than the actual amounts of that city.

The response rates are calculated by dividing the sum of valid questionnaires and the loss by the number of the handed-out questionnaires. Supplements 1 and 3 reflect the response rates of each school, city, country, and finally the European sample. The response rates were calculated by dividing the responded questionnaires by the number of the non-responded questionnaires. Thus, the amount of loss did not affect the response rates. While in Greece, Croatia, and Turkey the response rates were as high as 85-100 percent, some of other countries Germany and the Netherlands had the normal rates of 20-30 percent. The overall response rate 
was calculated to be 52.07 percent, which seems normal and acceptable for such a sample distributed in different countries.

According to Supplement 3, 120 questionnaires were considered as loss and were eliminated from the survey results because they had some deficien-cies such as more than one option selected for some important questions. The final validated or corrected questionnaires were 1304 in all case-study cities. For being informed about the missing data related to each question, the readers can refer to Supplement 4, where the number of valid and unanswered questions by respon-dents have been pointed out.

Five major urban form variables are meant to be developed for the future research, namely connectivity, accessibility to public transportation, accessibility to public/open spaces, population density, and city size. The method of variable development related to these indicators have been explained in Supplement 3. The data needed for these indicators, were provided by working on Google Maps, or using secondary census data. Here more information on the methods applied are offered.

Street network connectivity is an urban form variable that is considered to be a motivator of active travels, including walking and bicycling, i.e. more connected street networks are possible to encourage children and their parents for walking and biking to school. For estimating street connectivity, the number of street intersections were estimated by means of Google Maps. Every crossroad made by streets of any type, including main, secondary, or smaller allies within the catchment areas of rectangular $3^{*} 3 \mathrm{~km}$ zones centered by schools were manually counted. The estimated number of intersections were divided by the area of the catchment area, which was in most cases $9 \mathrm{~km}^{2}$. The exceptions were the cases, in which the pilot cities were located on see shore (Rijeka, HR) or the schools were located on the edge of the city (Doganshehir, TR). In such cases, the number of intersections were divided by an area smaller than $9 \mathrm{~km}^{2}$. Using the information offered by the website ÖPNVKARTE (http://www.öpnvkarte.de/), the location and number of public transportation stations within the catchment areas around schools were identified. The public transport stations include both bus stops and urban rail stations like U-Bahn in Berlin. The accessibility to public transport is assumed to have effect on public transport use of children, which is not an active transport mode. In case of Berlin, the location and number of public transport stations were collected from the website of Berliner Verkehrsbetriebe-BVG (http://fahrinfo.bvg.de/Fahrinfo/bin/query.bin/d $n$ ?\&ujm=1). The stations of all pilot cities were found on the above website, except the ones in Turkey and in Łódź, Poland. As a result, Turkish and Polish colleagues, manually counted the bus stops around the three schools.

As seen in the literature, presence of public open/green spaces such as playgrounds and large or local urban parks has influence on outdoor $\mathrm{PA}^{2}$ of children. It may also be linked to ATS. Hence, it has been tried to collect data about this availability within the surroundings of the schools. Four counting them, Google Maps has been the basis. All types of public spaces that may be used by children, for playing, passing time with friends or alone, and walking/biking have been counted on the online maps. Again, the basis was the catchment areas of $3 * 3 \mathrm{~km}^{2}$.

Population density is one of the most important indicators of urban form measured in this survey. The population residing in the catchment areas around schools were estimated by each partner separately. In Berlin, the population was estimated using free GIS materials including small statistical blocks located in the rectangular zones around schools. In Foggia, Italy, a share of the city population proportional to the areas of the zones was allocated to the catchment areas. Other partner cities took used data for calculating the populations. For that local demographic census data of the recent years was adopted.

City size refers to the population accommodated in the administrative urban boundaries of the pilot cities. Based on the secondary demographic data, it can be said if the pilot cities are major, large, small, or micro. Only the population of the cities have been used for this purpose, and the inhabitants of suburban areas (metropolitan populations) have not been considered; e.g., the urban population of Berlin City is 3.5 million, while it increases to about 4.2 million, when 
bringing in the suburban residents. In this study, only 3.5 million inhabitants have been allocated to Berlin.

The results of this data collection facilitates a cross-sectional study such as comparisons between different counties and regions, but there is still work to be done for providing a more rigorous survey providing ground for longitudinal studies. Since the time duration of the funding received from the European Commission was limited to two years, only a part of which was used for collecting data, there were no time for undertaking a follow up survey examining the changes in children's mobility patterns and body mass index or effective interventions. Lack of longitudinal studies are clear when reviewing the related literature. Due to difficulties and expenses of doing such data collections, only a limited number of surveys such as Rosenberg et al. (2006), Pabayo et al. (2010), Chillón et al. (2012), and Mendoza \& Liu (2014) have provided longitudinal data. In future attempts, providing data follow-up data from the target schools will be ambitious. Moreover, combining selfadministered questionnaires with instrumental measurement of body composition such as skin thickness can have good results so that the observations about children's body are not limited to the reported weight and height. This combination was not planned for the present survey due to limitations related to funding, expertise of the team, and budget.

Table 3 - The general descriptive statistics of the continuous data derived from the survey.

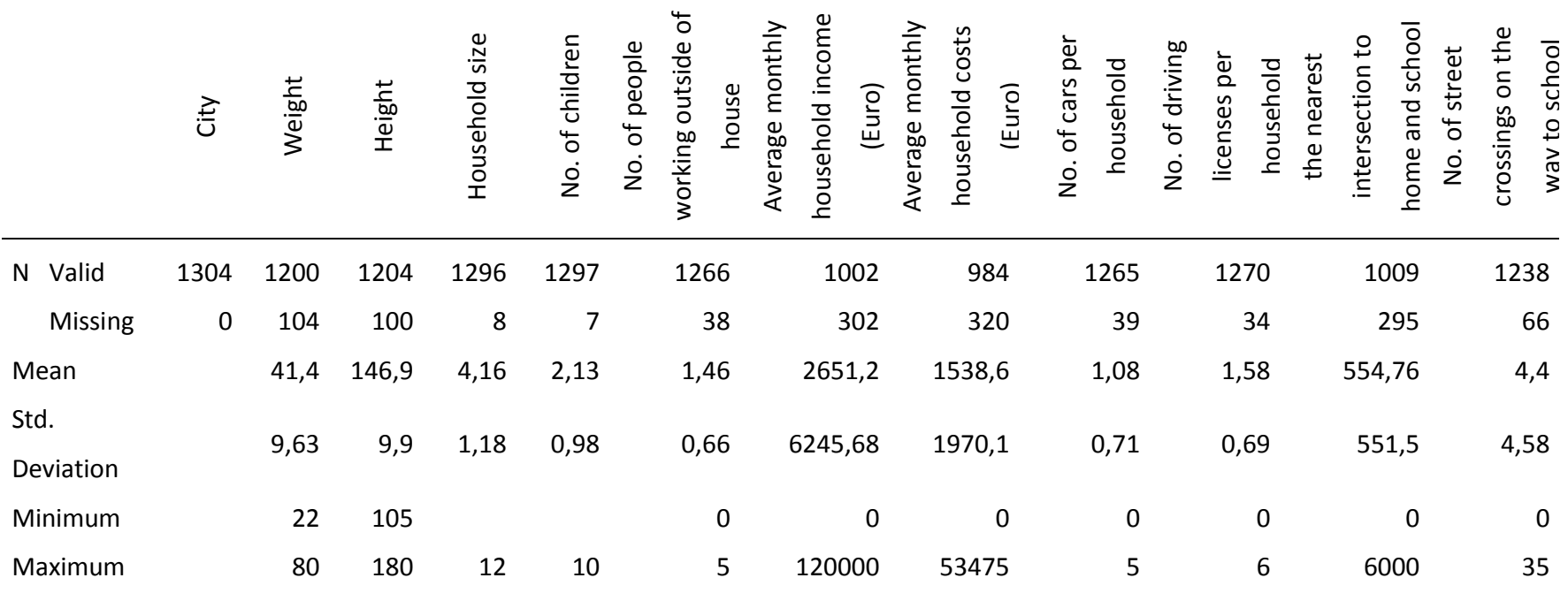

\section{Findings}

The dataset provided by this study fulfills the five objectives of this research that stem from five gaps in the existing knowledge about children's mobility and health. The surveys in seven countries provided data about only children with a narrow range of ages (excluding adolescents) with focus on less-studied European contexts as well as providing variables of land use and perceptions of parents and children. With this view, the below-explained findings succeeded to provide data for future studies with a strong focus on inter-contextual comparisons highlighting the differences in geography, culture, and climate. The findings of the survey are presented in two groups. The first part is related to continuous data. The findings of this part are shown in Table 3, where mean, standard deviation, minimum, and maximum are reflected. The breakdown of the data based on city are seen in Supplement 5. No comparison between the cities have been made in these presentations, and only raw data were input in them. The questions formulated in form of categorical and dummy data are collected in Supplement 6. The findings of this table include both city-level data and the overall findings of the sample of nine cities. 
Except one question (average monthly household costs) all the questions were answered by more than $1000 \mathrm{child} /$ parents and several of them were fully answered ( $\mathrm{N}=1304)$. Average monthly household income and costs were the two most difficult questions to get response about. This is in line with many other surveys. The monthly household ranged from $11553 €$ in Utrecht, NL to $896 €$ in Konstantynow, PL. These figures can be telling about the mobility attitudes of families, but a better indicator can be income divided by costs. By calculating this figure, the results will be more useful for findings associations. If so the proportion of income to costs in Utrecht will be 6.82 , while it is 1.26 . High income to cost ratio is also seen in Berlin with a proportion of 2.02.

The typical child of this sample was a 10-11-yearold with a weight of about $40 \mathrm{~kg}$ and a height of about $140 \mathrm{~cm}$. The houses of the sample located 554 meters away from the schools separated by an average of 4.4 junctions. $45 \%$ (readers can find the exact figures in the tables) of the households of the sample have four members in their households, which results to $50 \%$ with two children. An average of 1.46 persons work outside of the house, which indicates that one person works outside in $44 \%$ of households and two persons work in $48 \%$ of them. Interestingly, $43 \%$ of the children of the sample are not accompanied by anyone on the way to school. This is why $58 \%$ of them walk to school as the most dominant commuting mode amongst other choices.

Secondary data were collected in a way that four urban form variables can be developed. Supplement 7 shows the results of the estimations of urban form characteristics based on the methodology explained above. All four developed variables are expected to have positive effects (if significant) according to the literature.

\section{Discussion}

The overall sample shows higher share of active transportation (58\% walking and $8 \%$ bicycling) compared to a number of previous surveys. In the sample of Sarmiento et al. (2015) 37\% of children walked and $4.9 \%$ biked to school (see Table 1 ). $20 \%$ difference in walking rates may be because of the contexts of studies. they conducted their data collection in several countries with diverse cultures. The resulted mode choices are also higher than that of DeWeese \& Ohri-Vachaspati (2015) (47\% walking in a sample in New Jersey, USA), Mendoza \& Liu (2014) (9\% general active commuting in the USA), Ostergaard et al. (2013) (49\% walking and $4 \%$ bicycling in a Norwegian sample), (Larouche et al. 2011) (Canadian sample), Yeung et al. (2008) (34\% general active transportation in Australia), Rosenberg et al. (2006) $(20 \%$ in California, USA), (Heelan et al. 2005) (36\% active commuting in Nebraska, USA), and Fulton et al. (2005) (11\% walking and 3\% biking in the USA). However, the findings of this study about the rates of active transportation of children are approximately equal or less than those of Chillón et al. (2012) (35\% to 54\% walking and $12 \%$ to $31 \%$ biking in Sweden) and GutiérrezZornoza et al. (2015) (70\% in Cuenca, Spain). In general, the findings about the active commuting rates seem in line with the previous surveys, particularly when it is considered that commuting circumstances are often under the influence of culture, geography, and climate (refer to Table 1 for a summary of the discussed publications). These factors may cause inter or intra-contextual differences in active commuting to school or health conditions. In other words, the levels of active commuting and physical activity of children may be significantly different not only between socio-cultural, geographical, and climatic contexts, but also inside them between different groups. Recent research shows that factors related to children's active transportation and health are not limited to the built environment, mobility decisions, lifestyles, and perceptions, but also climate (Kallio et al. 2016) and the socioeconomic status (Duncan et al. 2008) inside a specified context can be important. Anyhow, the inter-contextual mismatches have not completely been investigated and need more examinations. That is true also for different contexts of Europe. This data collection provides a basis for future publications for finding out more about these contextual inquiries.

The findings of this survey reveal sheds light on appealing topics related to the differences in the mobility and body weight of children in different European cities and regions. A quick scanning of 
the results in Supplement 6 shows some of these subjects. An example the difference seen by a first glance between some cities with high personal car use as the main school commuting mode such as Foggia (35\%), Konstantynow (25\%), and Thessaloniki (29\%). Car use in these cities can be compared to that of cities with better urban development such as Berlin (11\%) and Utrecht $(10 \%)$ or cities with warmer weather and perhaps different culture such as Malatya (8\%), Doğanşehir $(7 \%)$, and Rijeka (6\%). The role of urban development can be seen in neighborhood shopping facilities in better-developed cities: $40 \%$ of parents in Berlin and $48.8 \%$ in Utrecht shop in their own neighborhood. The amount of parents satisfied with the neighborhood walking and biking facilities in Utrecht are much higher than other cities. These may have significant correlation with children's walking and biking to school. Preliminary scanning of the findings shows other interesting points that may significantly cause contextual differences in mobility habits and, as a result, in body weight: the percentage of mothers working are hugely different in different contexts. The percentage of mothers who do not work or do not commute is really small in some of the southern cities such as Malatya, Doğanşehir, and Thessaloniki compared to northern cities. This may be a significant determinant of children's commuting mode. Neighborhood safety and security have also points to tell us: in some cities like Doğanşehir, children as well as their parents have sense of lack of safety and security, but still they largely walk to school (82.9\%). This may be because of lack of alternative modes for them. The role of parental perceptions of safety and security can be observed in the number of children traveling to school independently. No meaningful differences are identified that can be connected to the regions or climates; in Berlin, Rijeka, Malatya, and Doğanşehir higher percentages of children go to school independently while this figure is lower in Utrecht by surprise. The role of cultures and economics can be seen in a number of issues, i.e. children's bike ownership in northern cities is considerably higher than the southern areas. All of the sample children in Utrecht, 94\% in Berlin, 94\% in Konstantynow, and $97 \%$ in Lodz have bicycles. In the south, this percentage is lower. Another point that catches attention in the first look to the findings is that the distance to school is not related to the size of the cities (Supplement 5). The above general observations need to be statistically tested in future investigations.

In the empirical studies following this data collection, the similarities and differences between mobility patterns, perceptions, and weight-related issues within the observed cities and countries of this survey will be statistically tested. The role of contextuality should receive more attention in these studies.

\section{Conclusion}

This study provides numerical and categorical data regarding the mobility patterns of children on the way to school and back home, the perceptions of safety and security, the physical environment, and the effects of all of the above the body weight of 9 to 12 -year-old children in Europe. This data collection program has benefits such as a good distribution of geographical contexts throughout the continent. The consistency of the survey structure in all countries enables comparative studies about the topic between the regions and cultures. The context specificity of the topic and extreme dependence to cultures and sub-cultures is probable but not so many studies have focused on this subject. The example of such studies has been done by Larouche et al. (2015), who showed the characteristics of active transport to school may differ in different cultures, so the interventions should not be uniform in all areas and regions. This hypothesis can be tested by the findings of this survey, not only about the characteristics of active commuting, but also about other targets of the questionnaires such as perceptions of safety and security as well as the effectiveness of urban form, accessibility, and the distances to schools.

The preliminary descriptive analysis of the findings gives the researchers of this survey that this specificity may be present in several points that have not been thoroughly examined in previous investigations. Thus using the results of this data collection, it will be possible to provide empirical evidence to prove such hypothesis 
regarding not only active commuting to school, but also other related phenomena. The on-going studies of the research team will be continued by a number of topics including the dependent commuting to school, differences between what parents and children perceive about safety and security of the environment, the associations of the urban form with body mass index, the importance of the quality of the built environment in active commuting to school, the correlations between the parental mobility habits with the children's commuting patterns, etc. All the above will be considered not only within the countries and cities, but also by comparing the phenomena in different regions such as the central/western Europe, southern areas, and south-eastern areas, as well as comparing between different city sizes. In addition, such questions like what the team of this study try to answer can be followed by colleagues by collecting data from countries not covered by this research.

\section{Acknowledgements}

This study has been conducted as a part of the project "Multisport Against Physical Sedentary"M.A.P.S. (project number 567236-EPP-1-2015-2IT-SPO-SCP) funded by the ERASMUS+ program of the European Commission. The funders had no role in undertaking this review. The paper is a rearrangement two reports submitted to the European Commission.

The authors would like to thank the following survey staff, who contributed to management of the survey in the selected schools by negotiating with schools' authorities, guiding participants about the questions, and/or translating the questionnaires from English to local languages and preparing them for distribution: Carla Calabrese (IT), Gordon E. Jamerson, B.Sc. (DE), Georgios Patsakas, M.Sc. (GR), Georgios Parisopoulos, M.Sc. (GR), loannis Meimaridis, B.Sc. (GR), Konstantinos Anagnostaras, M.Sc. (GR), Andreas Perrostis, B.Sc. (GR), Eleni Dessi, B.A. (GR), Toni Družeta, B.Sc. (HR), Tatjana Udović, M.A. (HR), Ingmar Daams, BA (NL), Paweł Drużek, M.A. (PL), and Ahmet Dalcı (TR).

\section{Notes}

${ }^{1} \mathrm{~A}$ note for readers, who do not come from transportation planning field: pedestrian sheds or catchment areas applied in this study are areas that can be walked or biked toward a destination from a certain point. Here the starting point is the nearest intersection and the destination is the school. In this study, the schools are the center of the catchment areas. catchment areas are widely used in urban transportation planning, especially for walking and walkability as well as Transit-Oriented Development (TOD). In case of TOD, the walking or biking from homes to the center of the areas (public transit stations) are the basis of analyses. The catchment areas can be defined based on aerial lines that make circular areas or according to streets that make polygons made up of polylines.

${ }^{2}$ The physical activity of children like playing or passing time with friends or classmates in open spaces that may be located in the surroundings of home such as playgrounds, small urban parks, local open and public spaces, etc.

\section{References}

Cao X, Mokhtarian PL, Handy SL (2009) Examining the impacts of residential self-selection on travel behaviour: A focus on empirical findings. Transport reviews 29:359-395

Chillón P, Ortega FB, Ruiz JR, Evenson KR, Labayen I, Martínez-Vizcaino $V$, Hurtig-Wennlöf A, Veidebaum T, Sjöström M (2012) Bicycling to school is associated with improvements in physical fitness over a 6-year follow-up period in Swedish children. Prev Med 55:108-112. doi: 10.1016/j.ypmed.2012.05.019

Cochran WG (1963) Sampling Techniques, 2nd edn. John Wiley and Sons, Inc., New York

DeWeese R, Ohri-Vachaspati P (2015) The Role of Distance in Examining the Association Between Active Commuting to School and Students' Weight Status. J Phys Act Health 12:1280-1288. doi: 10.1123/jpah.2014-0100

Dühr S (2005) Potentials for polycentric development in Europe: The ESPON 1.1.1 project report. Planning Practice and Research 20:235-239. doi: 10.1080/02697450500414728

Duncan EK, Duncan JS, Schofield G (2008) Pedometerdetermined physical activity and active transport in girls. Int J Behav Nutr Phys Act 5:2

Masoumi HE (2017) Active Transport to School and Children's Body Weight: A Systematic Review. 95-110 Paginazione / Tema. Journal of Land Use, Mobility and Environment, Vol 10, $\mathrm{N}^{\circ} 1$ (2017): Methods, tools and 
best practices to increase the capacity of urban systems to adapt to natural and man-made changes. doi: 10.6092/1970-9870/4088

Fulton JE, Shisler JL, Yore MM, Caspersen CJ (2005) Active transportation to school: findings from a national survey. Res Q Exerc Sport 76:352-357. doi: 10.1080/02701367.2005.10599306

Gutiérrez-Zornoza $M$, Sánchez-López $M$, GarcíaHermoso A, González-García A, Chillón P, MartínezVizcaíno V (2015) Active commuting to school, weight status, and cardiometabolic risk in children from rural areas: the Cuenca study. Health Educ Behav 42:231239. doi: $10.1177 / 1090198114549373$

Heelan KA, Donnelly JE, Jacobsen DJ, Mayo MS, Washburn R, Greene L (2005) Active commuting to and from school and $\mathrm{BMI}$ in elementary school children-preliminary data. Child Care Health Dev 31:341-349. doi: 10.1111/j.1365-2214.2005.00513.x

Heinen E, Chatterjee K (2015) The same mode again? An exploration of mode choice variability in Great Britain using the National Travel Survey. Transportation Research Part A: Policy and Practice 78:266-282

Kallio J, Turpeinen S, Hakonen H, Tammelin T (2016) Active commuting to school in Finland, the potential for physical activity increase in different seasons. International journal of circumpolar health 75:33319

Larouche R, Lloyd M, Knight E, Tremblay MS (2011) Relationship between Active School Transport and Body Mass Index in Grades-4-To-6 Children. Pediatric Exercise Science 23:322-330. doi: 10.1123/pes.23.3.322

Larouche R, Sarmiento OL, Broyles ST, Denstel KD, Church TS, Barreira TV, Chaput J-P, Fogelholm M, Hu G, Kuriyan R, Kurpad A, Lambert EV, Maher C, Maia J, Matsudo V, Olds T, Onywera V, Standage M, Tremblay MS, Tudor-Locke C, Zhao P, Katzmarzyk PT (2015) Are the correlates of active school transport contextspecific? Int J Obes Suppl 5:\$89-99. doi: 10.1038/ijosup.2015.25

Masoumi HE (in press) Associations of Built Environment and Children's Physical Activity: A Narrative Review. Reviews on Environmental Health

Mehdizadeh M, Nordfjaern T, Mamdoohi A (2016) The role of socio-economic, built environment and psychological factors in parental mode choice for their children in an Iranian setting. Transportation 12:317. doi: 10.1007/s11116-016-9737-z

Mendoza JA, Liu Y (2014) Active commuting to elementary school and adiposity: an observational study. Child Obes 10:34-41. doi: 10.1089/chi.2013.0133
Ostergaard L, Kolle E, Steene-Johannessen J, Anderssen SA, Andersen LB (2013) Cross sectional analysis of the association between mode of school transportation and physical fitness in children and adolescents. Int J Behav Nutr Phys Act 10:91. doi: 10.1186/1479-5868-10-91

Pabayo R, Gauvin L, Barnett TA, Nikiéma B, Séguin L (2010) Sustained active transportation is associated with a favorable body mass index trajectory across the early school years: findings from the Quebec Longitudinal Study of Child Development birth cohort. Prev Med 50 Suppl 1:S59-64. doi: 10.1016/j.ypmed.2009.08.014

Panter JR, Jones AP, van Sluijs EMF, Griffin SJ (2010) Neighborhood, route, and school environments and children's active commuting. Am J Prev Med 38:268278. doi: 10.1016/j.amepre.2009.10.040

Roque D, Masoumi HE (2016) An Analysis of Car Ownership in Latin American Cities: A Perspective for Future Research. Periodica Polytechnica. Transportation Engineering 44:5

Rosenberg DE, Sallis JF, Conway TL, Cain KL, McKenzie TL (2006) Active transportation to school over 2 years in relation to weight status and physical activity. Obesity (Silver Spring) 14:1771-1776. doi: 10.1038/oby.2006.204

Rothman L, Buliung R, To T, Macarthur C, Macpherson A, Howard A (2015) Associations between parents perception of traffic danger, the built environment and walking to school. Journal of Transport \& Health 2:327-335. doi: 10.1016/j.jth.2015.05.004

Sallis JF, Cerin E, Conway TL, Adams MA, Frank LD, Pratt M, Salvo D, Schipperijn J, Smith G, Cain KL, Davey R, Kerr J, Lai P-C, Mitáš J, Reis R, Sarmiento OL, Schofield G, Troelsen J, van Dyck D, Bourdeaudhuij I de, Owen N (2016) Physical activity in relation to urban environments in 14 cities worldwide: A crosssectional study. The Lancet 387:2207-2217. doi: 10.1016/S0140-6736(15)01284-2

Sarmiento OL, Lemoine P, Gonzalez SA, Broyles ST, Denstel KD, Larouche R, Onywera V, Barreira TV, Chaput J-P, Fogelholm M, Hu G, Kuriyan R, Kurpad A, Lambert EV, Maher C, Maia J, Matsudo V, Olds T, Standage M, Tremblay MS, Tudor-Locke C, Zhao P, Church TS, Katzmarzyk PT (2015) Relationships between active school transport and adiposity indicators in school-age children from low-, middleand high-income countries. Int J Obes Suppl 5:S10714. doi: 10.1038/ijosup.2015.27

Soltanzadeh H, Masoumi HE (2014) The Determinants of Transportation Mode Choice in the Middle Eastern Cities: The Kerman Case, Iran. Tema. Journal of Land Use, Mobility and Environment 7:199-222 
Sun Y, Liu Y, Tao F-B (2015) Associations Between Active Commuting to School, Body Fat, and Mental Well-being: Population-Based, Cross-Sectional Study in China. J Adolesc Health 57:679-685. doi: 10.1016/j.jadohealth.2015.09.002

Yeung J, Wearing S, Hills AP (2008) Child transport practices and perceived barriers in active commuting to school. Transportation Research Part A: Policy and Practice 42:895-900. doi: 10.1016/j.tra.2007.12.007

ÖPNVKARTE (2016) Public Transportation of Berlin. Retrieved from http://www.öpnvkarte.de/. Access date: 01.07.2016.
Hellenic Statistical Authority-ELSTAT Thessaloniki Census 2011.

Amt für Statistik Berlin-Brandenburg (2016), Bevölkerungsstand. Retrieved from www.statistikberlin-brandenburg.de. Access date: 03.07.2016.

Berliner Verkehrsbetriebe-BVG (2016). Retrieved from http://fahrinfo.bvg.de/Fahrinfo/bin/query.bin/dn?\&uj $\mathrm{m}=1$. Access date: 29.06.2016. 


\section{Supplementary material}

\section{Supplement 1 - Response rates and precision of the results}

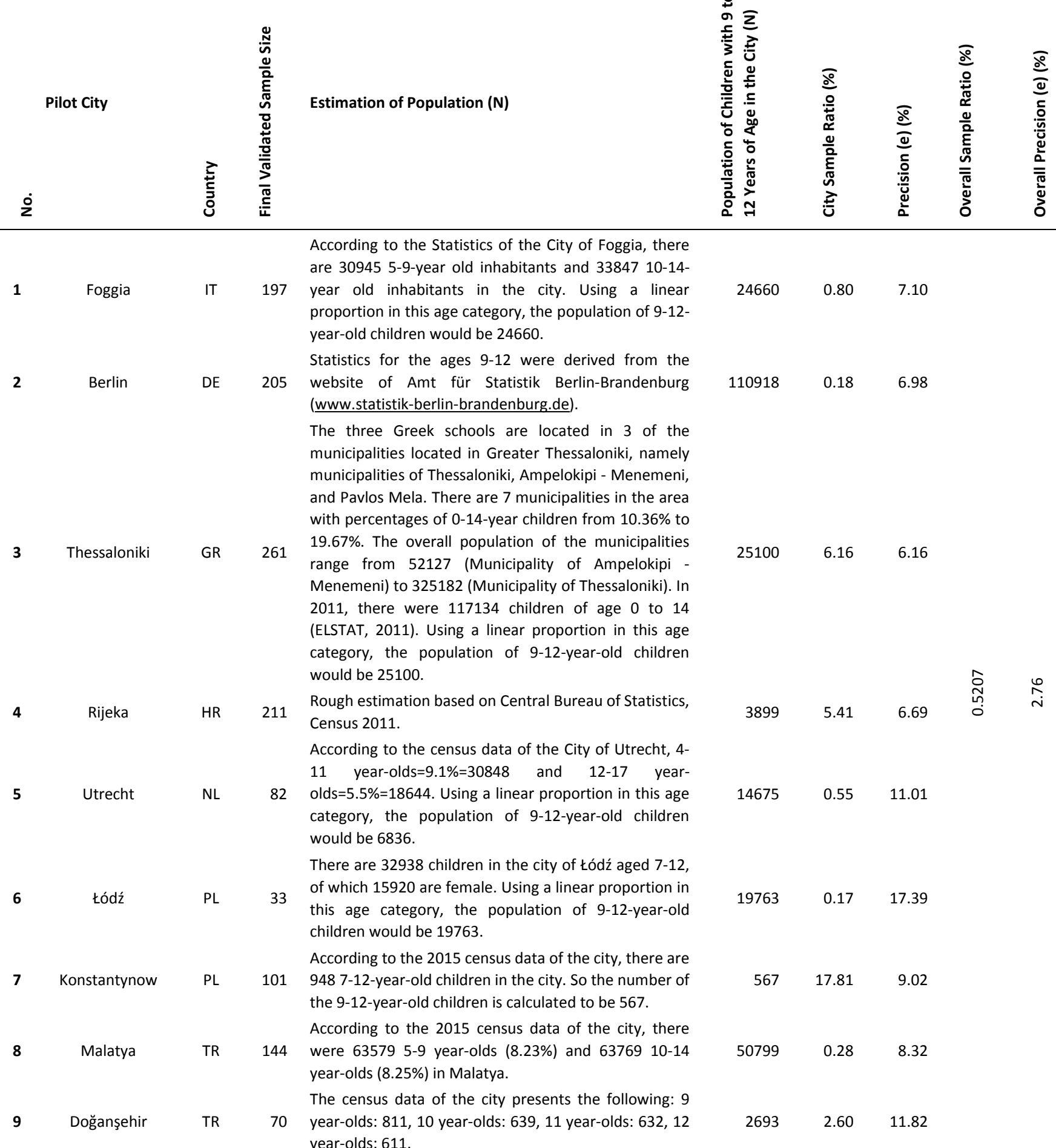


14. How often do you (parents) do your shopping in their neighborhood (near to your home)?

$\square \begin{aligned} & \text { never } \\ & \text { sometimes } \\ & 50-50\end{aligned}$

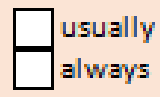

15. Do you (parents) do your entertainment activities mostly in their neighborhood (near to house)?

$\square \begin{aligned} & \text { never } \\ & \text { sometimes } \\ & 50-50\end{aligned}$

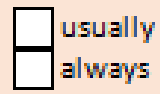

\section{Section 3: Travel to School}

16. Which crossroad is the nearest one to your home? Please show it on the map the interviewer shows you.

17. How does your child usually get to school and back home?

$\square$ walking $\square$ bybike/roller $\square$ by private/school service $\square$ by personal car $\square$ by publictransport

18. Which family member accompanies the child to school and back?

$\begin{array}{lll}\square \text { nobody } & \square \text { father } & \square \text { mother } \\ \text { 19. Does the child own a bike? } & \square \text { yes } & \square \text { no }\end{array}$

20. How many crossings are there between your home and the school?

\section{Section 4: Perceptions of the School Travel Routes}

21. How does the pupil (your child) feel about the safety of the routes to school, including sidewalks and bike lanes (if any) that connect your home to the school, in terms of traffic accidents that threaten your child? (this question goes to the pupil)
a very unsafe
$\square$ unsafe
a moderate
a safe
a very safe

22. How does the pupil (your child) feel about the security of the routes to school, including sidewalks and bike lanes (if any) that connect your home to the school, in terms of crime and abuse that threaten your child? (this question goes to the pupil)
a very insecure
$\square$ insecure
a moderate
a secure
a very secure

23. As a member of the house hold, how do you feel about the safety of the routes to school, including sidewalks and bike lanes (if any) that connect your home to the school, in terms of traffic accidents that threaten your child?
$\square$ very unsafe
a unsafe
$\square$ moderate
a safe
a very safe

24. As a member of the house hold, how do you feel about the security of the routes to school, including sidewalks and bike lanes (if any) that connect your home to the school, in terms of crime and abuse that threaten your child?
$\square$ very insecure
$\square$ insecure
a moderate
a secure
a very secure

25. How satisfied are you with the quality of sidewalks from home to your child's school?
a very dissatisfied
a dissatisfied
$\square$ indifferent
a satisfied a very satisfied

26. How satisfied are you with the quality of bike lanes/tracks/routes from home to your child's school?
$\square$ very dissatisfied
a dissatisfied
$\square$ indifferent
a satisfied
$\square$ very satisfied 
Supplement 3 - Response rates of the survey based on school, city, and country as well as the overall rates.

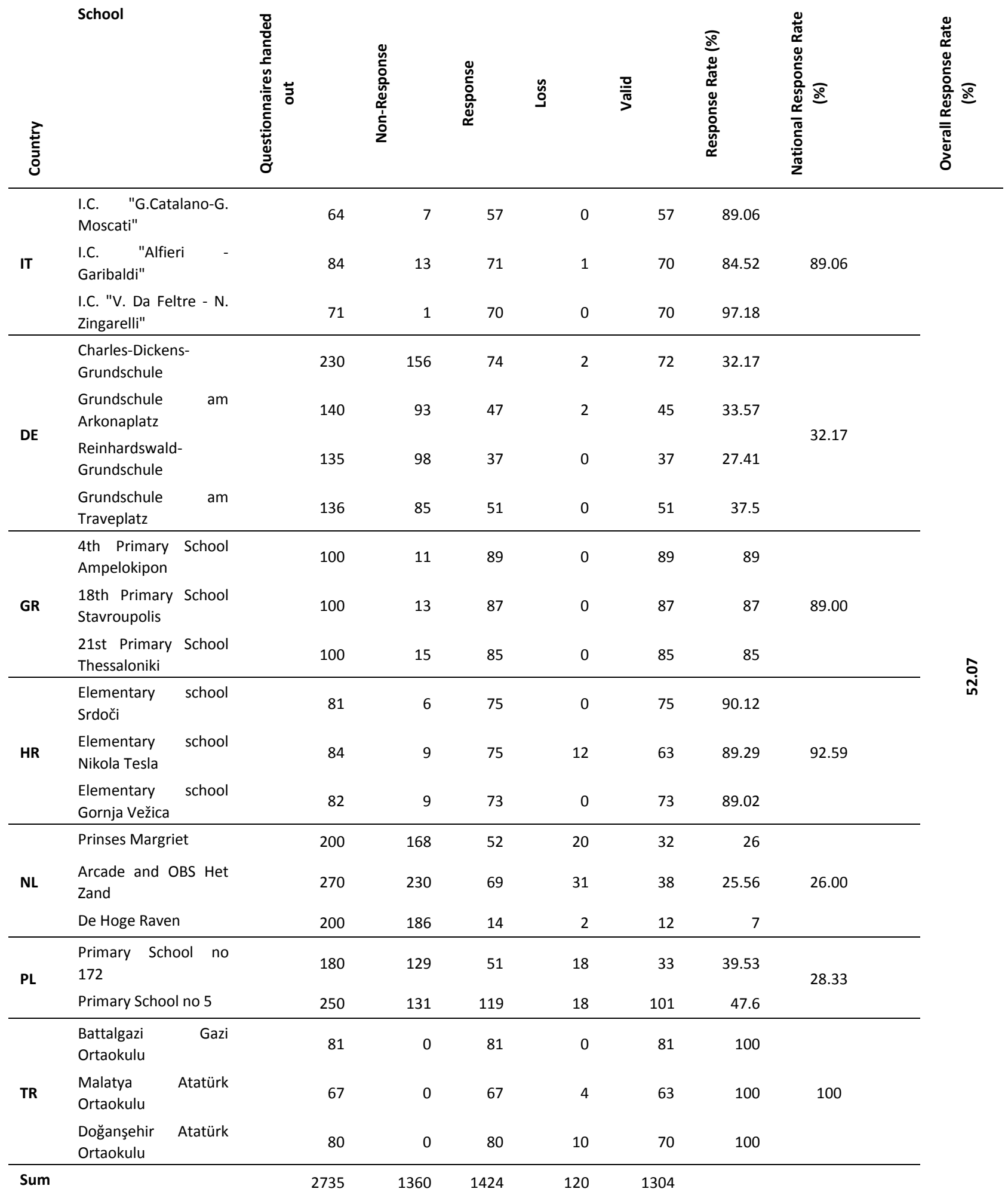




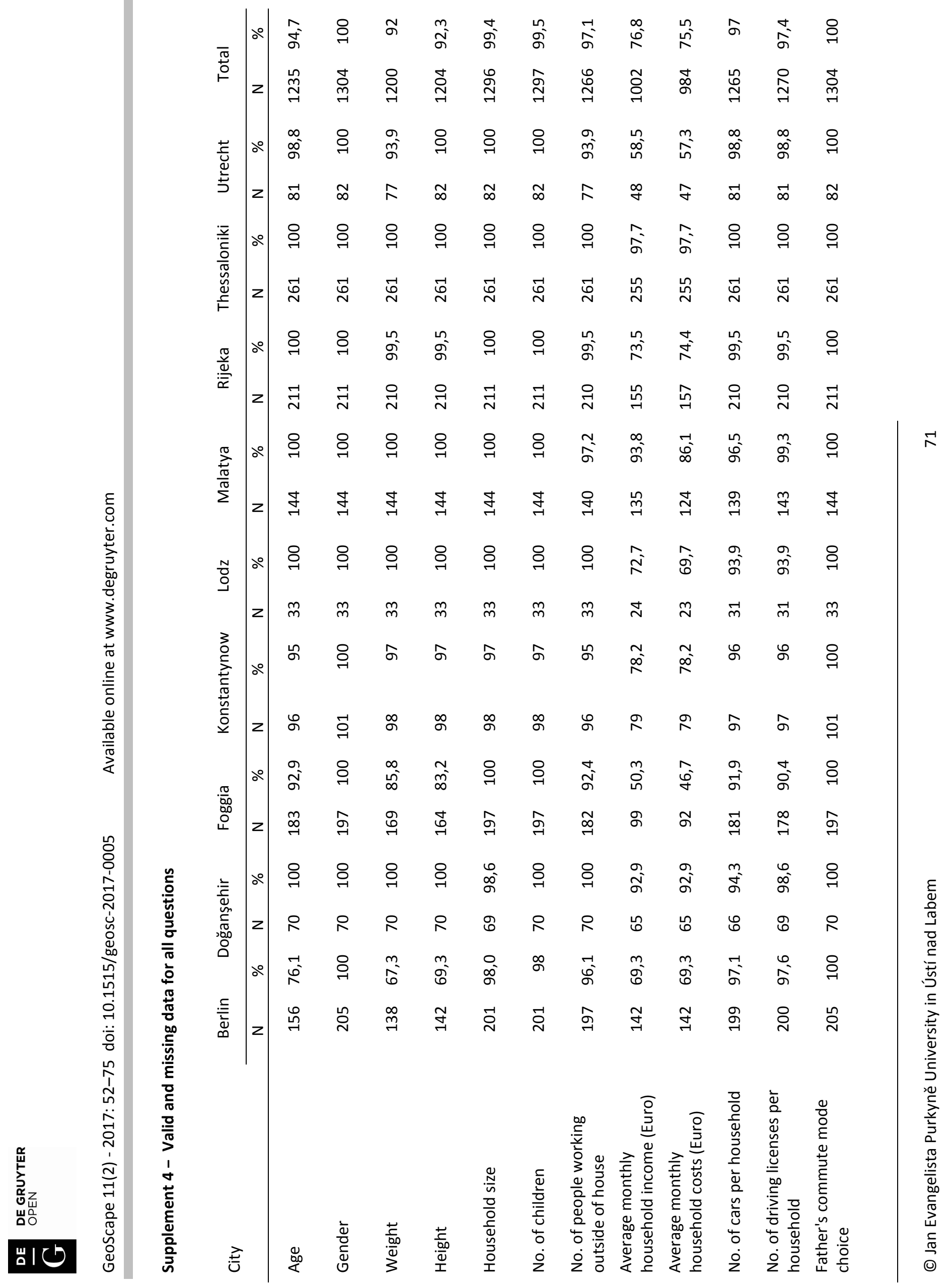


○

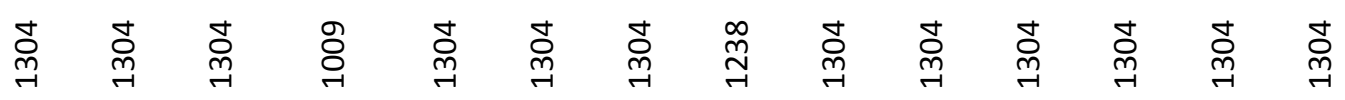
○

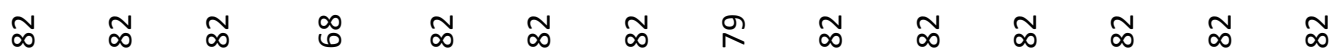
○ \& \&

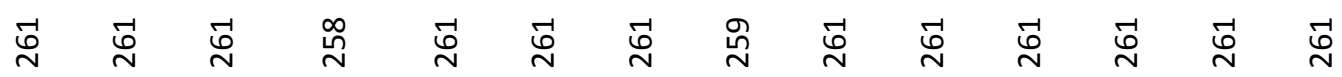
○ \&

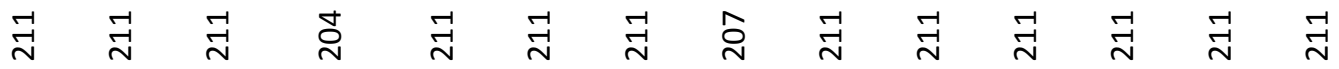
ᄋ \&

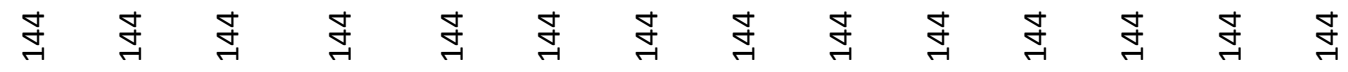
임 \&

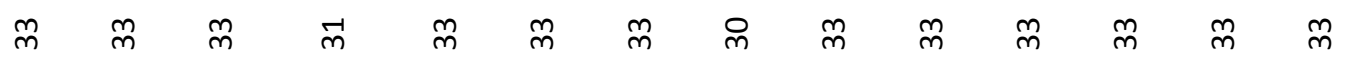
○

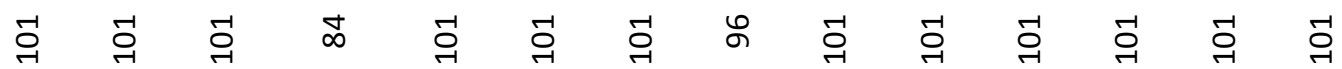
足

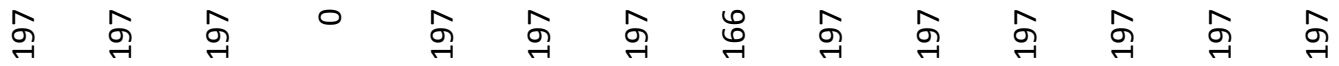
○

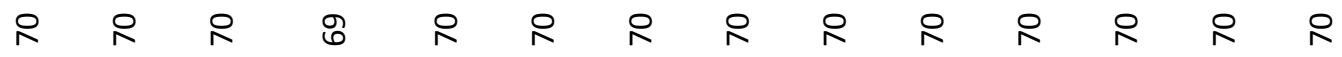
\&

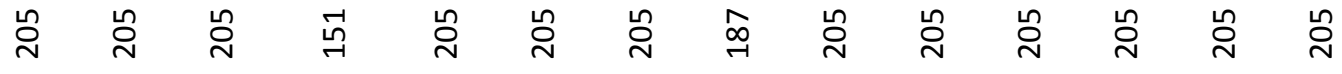


Supplement 5 - The descriptive statistics of the continuous data of the sample based on cities

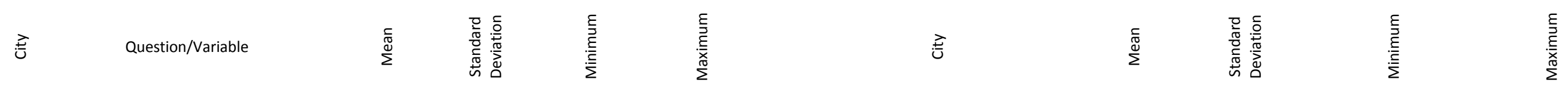

\begin{tabular}{|c|c|c|c|c|c|c|c|c|c|c|c|}
\hline \multirow{11}{*}{ 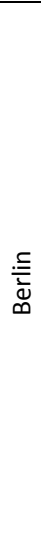 } & Weight & 38 & 9 & 24 & 74 & \multirow{11}{*}{ 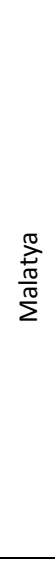 } & Weight & 41 & 9 & 24 & 68 \\
\hline & Height & 148 & 9 & 106 & 176 & & Height & 147 & 10 & 110 & 170 \\
\hline & Household size & 3,77 & 1,20 & 1,00 & 9,00 & & Household size & 5,03 & 1,56 & 0,00 & 12,00 \\
\hline & No. of children & 2,02 & 0,88 & 1,00 & 5,00 & & No. of children & 2,81 & 1,35 & 0,00 & 10,00 \\
\hline & No. of people working outside of house & 1,59 & 0,60 & 0,00 & 4,00 & & $\begin{array}{l}\text { No. of people working outside of } \\
\text { house }\end{array}$ & 1,01 & 0,63 & 0,00 & 4,00 \\
\hline & $\begin{array}{l}\text { Average monthly household income } \\
\text { (Euro) }\end{array}$ & 5576,58 & 6937,71 & 500,00 & 80000,00 & & $\begin{array}{l}\text { Average monthly household income } \\
\text { (Euro) }\end{array}$ & 2038,16 & 1355,34 & 100,00 & 8000,00 \\
\hline & Average monthly household costs (Euro) & 2766,18 & 1525,96 & 400,00 & 9000,00 & & $\begin{array}{l}\text { Average monthly household costs } \\
\text { (Euro) }\end{array}$ & 1419,88 & 950,66 & 200,00 & 5000,00 \\
\hline & No. of cars per household & 0,85 & 0,74 & 0,00 & 5,00 & & No. of cars per household & 0,65 & 0,65 & 0,00 & 3,00 \\
\hline & No. of driving licenses per household & 1,53 & 0,76 & 0,00 & 6,00 & & No. of driving licenses per household & 1,22 & 0,82 & 0,00 & 4,00 \\
\hline & $\begin{array}{l}\text { Distance between the nearest } \\
\text { intersection to home and school }\end{array}$ & 694 & 688 & 50 & 4500 & & $\begin{array}{l}\text { Distance between the nearest } \\
\text { intersection to home and school }\end{array}$ & 943 & 641 & 0 & 3000 \\
\hline & $\begin{array}{l}\text { No. of street crossings on the way to } \\
\text { school }\end{array}$ & 4,49 & 5,58 & 0,00 & 35,00 & & $\begin{array}{l}\text { No. of street crossings on the way to } \\
\text { school }\end{array}$ & 2,99 & 3,92 & 0,00 & 32,00 \\
\hline \multirow{11}{*}{ 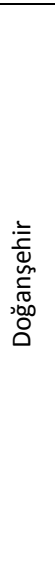 } & Weight & 39 & 9 & 25 & 72 & \multirow{11}{*}{ 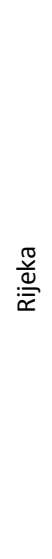 } & Weight & 45 & 10 & 22 & 78 \\
\hline & Height & 146 & 9 & 125 & 176 & & Height & 152 & 9 & 125 & 180 \\
\hline & Household size & 5,19 & 1,34 & 3,00 & 9,00 & & Household size & 3,99 & 1,03 & 2,00 & 12,00 \\
\hline & No. of children & 2,96 & 1,21 & 1,00 & 7,00 & & No. of children & 1,90 & 0,78 & 1,00 & 8,00 \\
\hline & No. of people working outside of house & 1,04 & 0,75 & 0,00 & 5,00 & & $\begin{array}{l}\text { No. of people working outside of } \\
\text { house }\end{array}$ & 1,68 & 0,58 & 0,00 & 3,00 \\
\hline & $\begin{array}{l}\text { Average monthly household income } \\
\text { (Euro) }\end{array}$ & 2057,55 & 2599,27 & 300,00 & 20000,00 & & $\begin{array}{l}\text { Average monthly household income } \\
\text { (Euro) }\end{array}$ & 1426,31 & 994,43 & 401,06 & 7316,94 \\
\hline & Average monthly household costs (Euro) & 1436,22 & 1500,32 & 200,00 & 10500,00 & & $\begin{array}{l}\text { Average monthly household costs } \\
\text { (Euro) }\end{array}$ & 1325,05 & 4210,00 & 332,58 & 53475,00 \\
\hline & No. of cars per household & 0,62 & 0,72 & 0,00 & 4,00 & & No. of cars per household & 1,20 & 0,66 & 0,00 & 4,00 \\
\hline & No. of driving licenses per household & 1,30 & 0,81 & 0,00 & 5,00 & & No. of driving licenses per household & 1,72 & 0,64 & 0,00 & 4,00 \\
\hline & $\begin{array}{l}\text { Distance between the nearest } \\
\text { intersection to home and school }\end{array}$ & 684 & 534 & 100 & 2000 & & $\begin{array}{l}\text { Distance between the nearest } \\
\text { intersection to home and school }\end{array}$ & 304 & 166 & 33 & 756 \\
\hline & $\begin{array}{l}\text { No. of street crossings on the way to } \\
\text { school }\end{array}$ & 3,14 & 3,31 & 0,00 & 25,00 & & $\begin{array}{l}\text { No. of street crossings on the way to } \\
\text { school }\end{array}$ & 2,10 & 1,61 & 0,00 & 15,00 \\
\hline \multirow{11}{*}{ 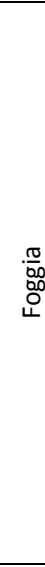 } & Weight & 43 & 9 & 23 & 70 & \multirow{11}{*}{ 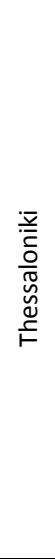 } & Weight & 43 & 10 & 25 & 80 \\
\hline & Height & 141 & 11 & 110 & 165 & & Height & 147 & 8 & 128 & 168 \\
\hline & Household size & 4,25 & 0,92 & 3,00 & 8,00 & & Household size & 3,97 & 0,90 & 1,00 & 7,00 \\
\hline & No. of children & 2,11 & 0,82 & 1,00 & 4,00 & & No. of children & 1,88 & 0,80 & 1,00 & 5,00 \\
\hline & No. of people working outside of house & 1,46 & 0,59 & 0,00 & 2,00 & & $\begin{array}{l}\text { No. of people working outside of } \\
\text { house }\end{array}$ & 1,56 & 0,50 & 1,00 & 2,00 \\
\hline & $\begin{array}{l}\text { Average monthly household income } \\
\text { (Euro) }\end{array}$ & 1737,37 & 929,84 & 0,00 & 6000,00 & & $\begin{array}{l}\text { Average monthly household income } \\
\text { (Euro) }\end{array}$ & 1599,53 & 663,84 & 700,00 & 4300,00 \\
\hline & Average monthly household costs (Euro) & 1516,30 & 693,93 & 0,00 & 3000,00 & & $\begin{array}{l}\text { Average monthly household costs } \\
\text { (Euro) }\end{array}$ & 1374,98 & 460,28 & 700,00 & 3500,00 \\
\hline & No. of cars per household & 1,46 & 0,64 & 0,00 & 5,00 & & No. of cars per household & 1,03 & 0,50 & 0,00 & 3,00 \\
\hline & No. of driving licenses per household & 1,80 & 0,49 & 1,00 & 4,00 & & No. of driving licenses per household & 1,47 & 0,52 & 1,00 & 3,00 \\
\hline & $\begin{array}{l}\text { Distance between the nearest } \\
\text { intersection to home and school }\end{array}$ & & & & & & $\begin{array}{l}\text { Distance between the nearest } \\
\text { intersection to home and school }\end{array}$ & 323 & 142 & 12 & 1200 \\
\hline & $\begin{array}{l}\text { No. of street crossings on the way to } \\
\text { school }\end{array}$ & 7,61 & 5,32 & 0,00 & 30,00 & & $\begin{array}{l}\text { No. of street crossings on the way to } \\
\text { school }\end{array}$ & 6,21 & 4,41 & 0,00 & 35,00 \\
\hline \multirow{11}{*}{ 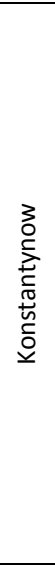 } & Weight & 39 & 9 & 25 & 71 & \multirow{11}{*}{ 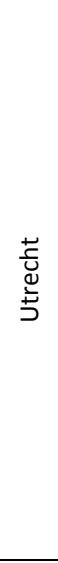 } & Weight & 37 & 8 & 25 & 64 \\
\hline & Height & 146 & 8 & 128 & 165 & & Height & 147 & 11 & 105 & 175 \\
\hline & Household size & 3,78 & 0,89 & 2,00 & 7,00 & & Household size & 4,12 & 1,09 & 0,00 & 6,00 \\
\hline & No. of children & 1,84 & 0,76 & 1,00 & 4,00 & & No. of children & 2,37 & 0,84 & 1,00 & 5,00 \\
\hline & No. of people working outside of house & 1,30 & 0,76 & 0,00 & 3,00 & & $\begin{array}{l}\text { No. of people working outside of } \\
\text { house }\end{array}$ & 1,68 & 0,85 & 0,00 & 4,00 \\
\hline & $\begin{array}{l}\text { Average monthly household income } \\
\text { (Euro) }\end{array}$ & 896,01 & 489,84 & 0 & 2365,00 & & $\begin{array}{l}\text { Average monthly household income } \\
\text { (Euro) }\end{array}$ & 11553,54 & 23164,35 & 970,00 & 120000,00 \\
\hline & Average monthly household costs (Euro) & 711,03 & 378,64 & 0 & 1802,00 & & $\begin{array}{l}\text { Average monthly household costs } \\
\text { (Euro) }\end{array}$ & 1694,68 & 1110,34 & 300,00 & 5500,00 \\
\hline & No. of cars per household & 1,30 & 0,72 & 0,00 & 4,00 & & No. of cars per household & 1,20 & 0,62 & 0,00 & 3,00 \\
\hline & No. of driving licenses per household & 1,73 & 0,78 & 0,00 & 4,00 & & No. of driving licenses per household & 1,78 & 0,67 & 0,00 & 4,00 \\
\hline & $\begin{array}{l}\text { Distance between the nearest } \\
\text { intersection to home and school }\end{array}$ & 694 & 870 & 5 & 6000 & & $\begin{array}{l}\text { Distance between the nearest } \\
\text { intersection to home and school }\end{array}$ & 742 & 486 & 100 & 2500 \\
\hline & $\begin{array}{l}\text { No. of street crossings on the way to } \\
\text { school }\end{array}$ & 3,01 & 2,19 & 0,00 & 15,00 & & $\begin{array}{l}\text { No. of street crossings on the way to } \\
\text { school }\end{array}$ & 2,38 & 1,70 & 0,00 & 8,00 \\
\hline \multirow{11}{*}{$\stackrel{N}{0}$} & Weight & 38 & 11 & 24 & 67 & & & & & & \\
\hline & Height & 144 & 9 & 130 & 161 & & & & & & \\
\hline & Household size & 4,06 & 1,09 & 2,00 & 8,00 & & & & & & \\
\hline & No. of children & 2,12 & 1,02 & 1,00 & 6,00 & & & & & & \\
\hline & No. of people working outside of house & 1,48 & 0,80 & 0,00 & 3,00 & & & & & & \\
\hline & $\begin{array}{l}\text { Average monthly household income } \\
\text { (Euro) }\end{array}$ & 1225,13 & 717,37 & 0 & 2928,00 & & & & & & \\
\hline & Average monthly household costs (Euro) & 772,57 & 306,52 & 225,00 & 1577,00 & & & & & & \\
\hline & No. of cars per household & 1,71 & 0,86 & 0,00 & 5,00 & & & & & & \\
\hline & No. of driving licenses per household & 1,81 & 0,65 & 0,00 & 3,00 & & & & & & \\
\hline & $\begin{array}{l}\text { Distance between the nearest } \\
\text { intersection to home and school }\end{array}$ & 580 & 618 & 10 & 2000 & & & & & & \\
\hline & $\begin{array}{l}\text { No. of street crossings on the way to } \\
\text { school }\end{array}$ & 5,67 & 7,58 & 0,00 & 30,00 & & & & & & \\
\hline
\end{tabular}


Supplement 6 - Frequencies and percentages related to the categorical data based on city-level data and the overall data of the sample of nine cities

\begin{tabular}{|c|c|c|c|c|c|c|c|c|c|c|c|}
\hline \multirow{2}{*}{\multicolumn{2}{|c|}{ Questions \& Options }} & \multicolumn{9}{|c|}{ City } & \multirow{3}{*}{$\begin{array}{c}\text { Total } \\
97(7,4 \%)\end{array}$} \\
\hline & & Berlin & Doğanşehir & Foggia & Konstantynow & Lodz & Malatya & Rijeka & Thessaloniki & Utrecht & \\
\hline \multirow{6}{*}{ 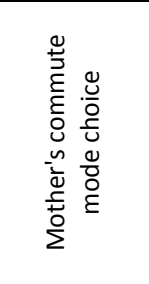 } & no response & $19(9,3 \%)$ & $0(0,0 \%)$ & $25(12,7 \%)$ & $11(10,9 \%)$ & $6(18,2 \%)$ & $0(0,0 \%)$ & $1(0,5 \%)$ & $4(1,5 \%)$ & $31(37,8 \%)$ & \\
\hline & bike & $40(19,5 \%)$ & $0(0,0 \%)$ & $11(5,6 \%)$ & $8(7,9 \%)$ & $1(3,0 \%)$ & $0(0,0 \%)$ & $1(0,5 \%)$ & $0(0,0 \%)$ & $21(25,6 \%)$ & $82(6,3 \%)$ \\
\hline & by foot & $25(12,2 \%)$ & $0(0,0 \%)$ & $30(15,2 \%)$ & $21(20,8 \%)$ & $2(6,1 \%)$ & $0(0,0 \%)$ & $38(18,0 \%)$ & $27(10,3 \%)$ & $0(0,0 \%)$ & $143(11,0 \%)$ \\
\hline & car & $45(22,0 \%)$ & $2(2,9 \%)$ & $59(29,9 \%)$ & $47(46,5 \%)$ & $20(60,6 \%)$ & $1(0,7 \%)$ & $77(36,5 \%)$ & $47(18,0 \%)$ & $13(15,9 \%)$ & $311(23,8 \%)$ \\
\hline & public transport & $67(32,7 \%)$ & $2(2,9 \%)$ & $42(21,3 \%)$ & $9(8,9 \%)$ & $4(12,1 \%)$ & $8(5,6 \%)$ & $67(31,8 \%)$ & $69(26,4 \%)$ & $4(4,9 \%)$ & $272(20,9 \%)$ \\
\hline & she doesn't work & $9(4,4 \%)$ & $66(94,3 \%)$ & $30(15,2 \%)$ & $5(5,0 \%)$ & $0(0,0 \%)$ & $135(93,8 \%)$ & $27(12,8 \%)$ & $114(43,7 \%)$ & $13(15,9 \%)$ & $399(30,6 \%)$ \\
\hline \multirow{6}{*}{ 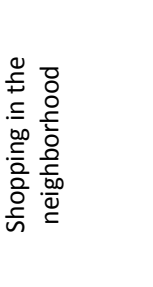 } & no response & $2(1,0 \%)$ & $0(0,0 \%)$ & $35(17,8 \%)$ & $3(3,0 \%)$ & $0(0,0 \%)$ & $5(3,5 \%)$ & $0(0,0 \%)$ & $1(0,4 \%)$ & $1(1,2 \%)$ & $47(3,6 \%)$ \\
\hline & $50-50$ & $29(14,1 \%)$ & $4(5,7 \%)$ & $31(15,7 \%)$ & $18(17,8 \%)$ & $4(12,1 \%)$ & $10(6,9 \%)$ & $20(9,5 \%)$ & $57(21,8 \%)$ & $1(1,2 \%)$ & $174(13,3 \%)$ \\
\hline & always & $81(39,5 \%)$ & $7(10,0 \%)$ & $27(13,7 \%)$ & $16(15,8 \%)$ & $3(9,1 \%)$ & $18(12,5 \%)$ & $65(30,8 \%)$ & $35(13,4 \%)$ & $40(48,8 \%)$ & $292(22,4 \%)$ \\
\hline & never & $3(1,5 \%)$ & $1(1,4 \%)$ & $23(11,7 \%)$ & $2(2,0 \%)$ & $0(0,0 \%)$ & $0(0,0 \%)$ & $7(3,3 \%)$ & $6(2,3 \%)$ & $0(0,0 \%)$ & $42(3,2 \%)$ \\
\hline & sometimes & $13(6,3 \%)$ & $44(62,9 \%)$ & $36(18,3 \%)$ & $10(9,9 \%)$ & $8(24,2 \%)$ & $62(43,1 \%)$ & $67(31,8 \%)$ & $28(10,7 \%)$ & $9(11,0 \%)$ & $277(21,2 \%)$ \\
\hline & usually & $77(37,6 \%)$ & $14(20,0 \%)$ & $45(22,8 \%)$ & $52(51,5 \%)$ & $18(54,5 \%)$ & $49(34,0 \%)$ & $52(24,6 \%)$ & $134(51,3 \%)$ & $31(37,8 \%)$ & $472(36,2 \%)$ \\
\hline \multirow{6}{*}{ 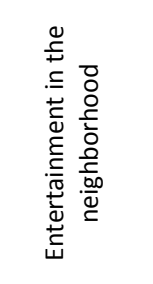 } & no response & $4(2,0 \%)$ & $1(1,4 \%)$ & $29(14,7 \%)$ & $4(4,0 \%)$ & $0(0,0 \%)$ & $3(2,1 \%)$ & $0(0,0 \%)$ & $0(0,0 \%)$ & $2(2,4 \%)$ & $43(3,3 \%)$ \\
\hline & $50-50$ & $46(22,4 \%)$ & $5(7,1 \%)$ & $29(14,7 \%)$ & $20(19,8 \%)$ & $4(12,1 \%)$ & $14(9,7 \%)$ & $17(8,1 \%)$ & $42(16,1 \%)$ & $16(19,5 \%)$ & $193(14,8 \%)$ \\
\hline & always & $3(1,5 \%)$ & $3(4,3 \%)$ & $19(9,6 \%)$ & $8(7,9 \%)$ & $1(3,0 \%)$ & $11(7,6 \%)$ & $13(6,2 \%)$ & $30(11,5 \%)$ & $7(8,5 \%)$ & $95(7,3 \%)$ \\
\hline & never & $16(7,8 \%)$ & $19(27,1 \%)$ & $31(15,7 \%)$ & $2(2,0 \%)$ & $3(9,1 \%)$ & $17(11,8 \%)$ & $52(24,6 \%)$ & $8(3,1 \%)$ & $5(6,1 \%)$ & $153(11,7 \%)$ \\
\hline & sometimes & $86(42,0 \%)$ & $29(41,4 \%)$ & $49(24,9 \%)$ & $20(19,8 \%)$ & $11(33,3 \%)$ & $68(47,2 \%)$ & $102(48,3 \%)$ & $32(12,3 \%)$ & $19(23,2 \%)$ & $416(31,9 \%)$ \\
\hline & usually & $50(24,4 \%)$ & $13(18,6 \%)$ & $40(20,3 \%)$ & $47(46,5 \%)$ & $14(42,4 \%)$ & $31(21,5 \%)$ & $27(12,8 \%)$ & $149(57,1 \%)$ & $33(40,2 \%)$ & $404(31,0 \%)$ \\
\hline \multirow{6}{*}{ 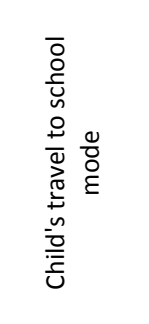 } & no response & $7(3,4 \%)$ & $0(0,0 \%)$ & $17(8,6 \%)$ & $21(20,8 \%)$ & $4(12,1 \%)$ & $0(0,0 \%)$ & $0(0,0 \%)$ & $1(0,4 \%)$ & $9(11,0 \%)$ & $59(4,5 \%)$ \\
\hline & bike & $30(14,6 \%)$ & $0(0,0 \%)$ & $15(7,6 \%)$ & $5(5,0 \%)$ & $4(12,1 \%)$ & $3(2,1 \%)$ & $5(2,4 \%)$ & $2(0,8 \%)$ & $28(34,1 \%)$ & $92(7,1 \%)$ \\
\hline & by foot & $104(50,7 \%)$ & $58(82,9 \%)$ & $43(21,8 \%)$ & $47(46,5 \%)$ & $14(42,4 \%)$ & $89(61,8 \%)$ & $186(88,2 \%)$ & $180(69,0 \%)$ & $31(37,8 \%)$ & $752(57,7 \%)$ \\
\hline & $\begin{array}{c}\text { by private/school } \\
\text { service }\end{array}$ & $0(0,0 \%)$ & $6(8,6 \%)$ & $0(0,0 \%)$ & $0(0,0 \%)$ & $0(0,0 \%)$ & $38(26,4 \%)$ & $0(0,0 \%)$ & $0(0,0 \%)$ & $6(7,3 \%)$ & $50(3,8 \%)$ \\
\hline & by public transport & $42(20,5 \%)$ & $1(1,4 \%)$ & $53(26,9 \%)$ & $3(3,0 \%)$ & $0(0,0 \%)$ & $3(2,1 \%)$ & $8(3,8 \%)$ & $3(1,1 \%)$ & $0(0,0 \%)$ & $113(8,7 \%)$ \\
\hline & own car & $22(10,7 \%)$ & $5(7,1 \%)$ & $69(35,0 \%)$ & $25(24,8 \%)$ & $11(33,3 \%)$ & $11(7,6 \%)$ & $12(5,7 \%)$ & $75(28,7 \%)$ & $8(9,8 \%)$ & $238(18,3 \%)$ \\
\hline \multirow{5}{*}{ 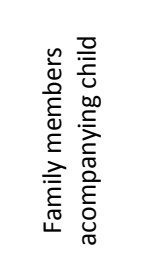 } & no response & $7(3,4 \%)$ & $0(0,0 \%)$ & $32(16,2 \%)$ & $23(22,8 \%)$ & $10(30,3 \%)$ & $1(0,7 \%)$ & 0 & 0 & $22(26,8 \%)$ & $95(7,3 \%)$ \\
\hline & father & $22(10,7 \%)$ & $14(20,0 \%)$ & $38(19,3 \%)$ & $11(10,9 \%)$ & $2(6,1 \%)$ & $26(18,1 \%)$ & $23(10,9 \%)$ & $17(6,5 \%)$ & $5(6,1 \%)$ & $158(12,1 \%)$ \\
\hline & mother & $42(20,5 \%)$ & $8(11,4 \%)$ & $70(35,5 \%)$ & $19(18,8 \%)$ & $8(24,2 \%)$ & $34(23,6 \%)$ & $27(12,8 \%)$ & $101(38,7 \%)$ & $29(35,4 \%)$ & $338(25,9 \%)$ \\
\hline & no one & $127(62,0 \%)$ & $36(51,4 \%)$ & $48(24,4 \%)$ & $34(33,7 \%)$ & $11(33,3 \%)$ & $72(50,0 \%)$ & $143(67,8 \%)$ & $61(23,4 \%)$ & $26(31,7 \%)$ & $558(42,8 \%)$ \\
\hline & $\begin{array}{l}\text { siblings/close } \\
\text { relatives/others }\end{array}$ & $7(3,4 \%)$ & $12(17,1 \%)$ & $9(4,6 \%)$ & $14(13,9 \%)$ & $2(6,1 \%)$ & $11(7,6 \%)$ & $18(8,5 \%)$ & $82(31,4 \%)$ & $0(0,0 \%)$ & $155(11,9 \%)$ \\
\hline & no response & $6(2,9 \%)$ & $0(0,0 \%)$ & $2(1,0 \%)$ & $3(3,0 \%)$ & $0(0,0 \%)$ & $0(0,0 \%)$ & $0(0,0 \%)$ & $1(0,4 \%)$ & $0(0,0 \%)$ & $12(0,9 \%)$ \\
\hline$\sum_{3}^{\frac{\Phi}{J}} . ?$ & no & $7(3,4 \%)$ & $29(41,4 \%)$ & $41(20,8 \%)$ & $3(3,0 \%)$ & $1(3,0 \%)$ & $52(36,1 \%$ & $52(24,6 \%)$ & $67(25,7 \%)$ & $0(0,0 \%)$ & $252(19,3 \%)$ \\
\hline & yes & $192(93,7 \%)$ & $41(58,6 \%)$ & $154(78,2 \%)$ & $95(94,1 \%)$ & $32(97,0 \%)$ & $92(63,9 \%)$ & $159(75,4 \%)$ & $193(73,9 \%)$ & $82(100,0 \%)$ & $1040(79,8 \%)$ \\
\hline ¿ & no response & $6(2,9 \%)$ & $0(0,0 \%)$ & $36(18,3 \%)$ & $5(5,0 \%)$ & $0(0,0 \%)$ & $4(2,8 \%)$ & $2(0,9 \%)$ & $0(0,0 \%)$ & $0(0,0 \%)$ & $53(4,1 \%)$ \\
\hline 을 & moderate & $67(32,7 \%)$ & $20(28,6 \%)$ & $71(36,0 \%)$ & $42(41,6 \%)$ & $18(54,5 \%)$ & $55(38,2 \%)$ & $65(30,8 \%)$ & $78(29,9 \%)$ & $30(36,6 \%)$ & $446(34,2 \%)$ \\
\hline$\stackrel{\overrightarrow{0}}{Q} \vec{d}$ & safe & $81(39,5 \%)$ & $9(12,9 \%)$ & $22(11,2 \%)$ & $33(32,7 \%)$ & $7(21,2 \%)$ & $37(25,7 \%)$ & $82(38,9 \%)$ & $93(35,6 \%)$ & $37(45,1 \%)$ & $401(30,8 \%)$ \\
\hline 岕 & unsafe & $22(10,7 \%)$ & $18(25,7 \%)$ & $47(23,9 \%)$ & $15(14,9 \%)$ & $5(15,2 \%)$ & $21(14,6 \%)$ & $17(8,1 \%)$ & $25(9,6 \%)$ & $4(4,9 \%)$ & $174(13,3 \%)$ \\
\hline$\frac{n}{0}$ & very safe & $23(11,2 \%)$ & $2(2,9 \%)$ & $3(1,5 \%)$ & $1(1,0 \%)$ & $2(6,1 \%)$ & $6(4,2 \%)$ & $33(15,6 \%)$ & $58(22,2 \%)$ & $9(11,0 \%)$ & $137(10,5 \%)$ \\
\hline & very unsafe & $6(2,9 \%)$ & $21(30,0 \%)$ & $18(9,1 \%)$ & $5(5,0 \%)$ & $1(3,0 \%)$ & $21(14,6 \%)$ & $12(5,7 \%)$ & $7(2,7 \%)$ & $2(2,4 \%)$ & $93(7,1 \%)$ \\
\hline 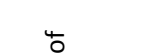 & no response & $5(2,4 \%)$ & $1(1,4 \%)$ & $40(20,3 \%)$ & $6(5,9 \%)$ & $0(0,0 \%)$ & $2(1,4 \%)$ & $0(0,0 \%)$ & $1(0,4 \%)$ & $0(0,0 \%)$ & $55(4,2 \%)$ \\
\hline$\underline{\underline{\sigma}}$ & insecure & $19(9,3 \%)$ & $15(21,4 \%)$ & $40(20,3 \%)$ & $15(14,9 \%)$ & $3(9,1 \%)$ & $25(17,4 \%)$ & $14(6,6 \%)$ & $28(10,7 \%)$ & $4(4,9 \%)$ & $163(12,5 \%)$ \\
\hline 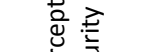 & moderate & $54(26,3 \%)$ & $21(30,0 \%)$ & $67(34,0 \%)$ & $39(38,6 \%)$ & $15(45,5 \%)$ & $51(35,4 \%)$ & $71(33,6 \%)$ & $84(32,2 \%)$ & $22(26,8 \%)$ & $424(32,5 \%)$ \\
\hline 这 & secure & $98(47,8 \%)$ & $8(11,4 \%)$ & $28(14,2 \%)$ & $35(34,7 \%)$ & $14(42,4 \%)$ & $32(22,2 \%)$ & $98(46,4 \%)$ & $86(33,0 \%)$ & $44(53,7 \%)$ & $443(34,0 \%)$ \\
\hline$\frac{0}{0}$ & very insecure & $5(2,4 \%)$ & $20(28,6 \%)$ & $20(10,2 \%)$ & $2(2,0 \%)$ & $1(3,0 \%)$ & $28(19,4 \%)$ & $3(1,4 \%)$ & $7(2,7 \%)$ & $1(1,2 \%)$ & $87(6,7 \%)$ \\
\hline & very secure & $24(11,7 \%)$ & $5(7,1 \%)$ & $2(1,0 \%)$ & $4(4,0 \%)$ & $0(0,0 \%)$ & $6(4,2 \%)$ & $25(11,8 \%)$ & $55(21,1 \%)$ & $11(13,4 \%)$ & $132(10,1 \%)$ \\
\hline & no response & $2(1,0 \%)$ & $1(1,4 \%)$ & $41(20,8 \%)$ & $5(5,0 \%)$ & $0(0,0 \%)$ & $1(0,7 \%)$ & $0(0,0 \%)$ & $0(0,0 \%)$ & $0(0,0 \%)$ & $50(3,8 \%)$ \\
\hline & moderate & $57(27,8 \%)$ & $23(32,9 \%)$ & $86(43,7 \%)$ & $40(39,6 \%)$ & $12(36,4 \%)$ & $52(36,1 \%)$ & $85(40,3 \%)$ & $77(29,5 \%)$ & $36(43,9 \%)$ & 468 (35,9\%) \\
\hline 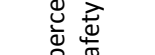 & safe & $71(34,6 \%)$ & $8(11,4 \%)$ & $27(13,7 \%)$ & $27(26,7 \%)$ & $9(27,3 \%)$ & $31(21,5 \%)$ & $70(33,2 \%)$ & $91(34,9 \%)$ & $31(37,8 \%)$ & $365(28,0 \%)$ \\
\hline 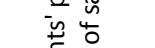 & unsafe & $54(26,3 \%)$ & $19(27,1 \%)$ & $28(14,2 \%)$ & $19(18,8 \%)$ & $9(27,3 \%)$ & $32(22,2 \%)$ & $26(12,3 \%)$ & $28(10,7 \%)$ & $7(8,5 \%)$ & $222(17,0 \%)$ \\
\hline$\frac{\bar{d}}{\frac{0}{\sigma}}$ & very safe & $14(6,8 \%)$ & $0(0,0 \%)$ & $5(2,5 \%)$ & $1(1,0 \%)$ & $1(3,0 \%)$ & $5(3,5 \%)$ & $18(8,5 \%)$ & $53(20,3 \%)$ & $5(6,1 \%)$ & $102(7,8 \%)$ \\
\hline & very unsafe & $7(3,4 \%)$ & $19(27,1 \%)$ & $10(5,1 \%)$ & $9(8,9 \%)$ & $2(6,1 \%)$ & $23(16,0 \%)$ & $12(5,7 \%)$ & $12(4,6 \%)$ & $3(3,7 \%)$ & $97(7,4 \%)$ \\
\hline & no response & $4(2,0 \%)$ & $1(1,4 \%)$ & $41(20,8 \%)$ & $7(6,9 \%)$ & $0(0,0 \%)$ & $1(0,7 \%)$ & $0(0,0 \%)$ & $0(0,0 \%)$ & $0(0,0 \%)$ & $54(4,1 \%)$ \\
\hline & insecure & $35(17,1 \%)$ & $21(30,0 \%)$ & $26(13,2 \%)$ & $12(11,9 \%)$ & $7(21,2 \%)$ & $30(20,8 \%)$ & $24(11,4 \%)$ & $25(9,6 \%)$ & $1(1,2 \%)$ & $181(13,9 \%)$ \\
\hline 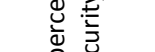 & moderate & $61(29,8 \%)$ & $20(28,6 \%)$ & $76(38,6 \%)$ & $45(44,6 \%)$ & $14(42,4 \%)$ & $51(35,4 \%)$ & $95(45,0 \%)$ & $91(34,9 \%)$ & $28(34,1 \%)$ & $481(36,9 \%)$ \\
\hline & secure & $84(41,0 \%)$ & $10(14,3 \%)$ & $39(19,8 \%)$ & $30(29,7 \%)$ & $11(33,3 \%)$ & $29(20,1 \%)$ & $77(36,5 \%)$ & $84(32,2 \%)$ & $45(54,9 \%)$ & $409(31,4 \%)$ \\
\hline 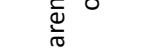 & very insecure & $4(2,0 \%)$ & $16(22,9 \%)$ & $10(5,1 \%)$ & $4(4,0 \%)$ & $1(3,0 \%)$ & $25(17,4 \%)$ & $1(0,5 \%)$ & $11(4,2 \%)$ & $1(1,2 \%)$ & $73(5,6 \%)$ \\
\hline & very secure & $17(8,3 \%)$ & $2(2,9 \%)$ & $5(2,5 \%)$ & $3(3,0 \%)$ & $0(0,0 \%)$ & $8(5,6 \%)$ & $14(6,6 \%)$ & $50(19,2 \%)$ & $7(8,5 \%)$ & $106(8,1 \%)$ \\
\hline & no response & $1(0,5 \%)$ & $2(2,9 \%)$ & $44(22,3 \%)$ & $7(6,9 \%)$ & $0(0,0 \%)$ & $0(0,0 \%)$ & $0(0,0 \%)$ & $0(0,0 \%)$ & $0(0,0 \%)$ & $54(4,1 \%)$ \\
\hline \pm 4 & dissatisfied & $30(14,6 \%)$ & $22(31,4 \%)$ & $36(18,3 \%)$ & $26(25,7 \%)$ & $15(45,5 \%)$ & $25(17,4 \%)$ & $51(24,2 \%)$ & $69(26,4 \%)$ & $12(14,6 \%)$ & $286(21,9 \%)$ \\
\hline 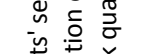 & indifferent & $26(12,7 \%)$ & $15(21,4 \%)$ & $44(22,3 \%)$ & $14(13,9 \%)$ & $3(9,1 \%)$ & $60(41,7 \%)$ & $27(12,8 \%)$ & $57(21,8 \%)$ & $22(26,8 \%)$ & $268(20,6 \%)$ \\
\hline & satisfied & $120(58,5 \%)$ & $15(21,4 \%)$ & $42(21,3 \%)$ & $45(44,6 \%)$ & $10(30,3 \%)$ & $41(28,5 \%)$ & $101(47,9 \%)$ & $64(24,5 \%)$ & $40(48,8 \%)$ & $478(36,7 \%)$ \\
\hline & very dissatisfied & $6(2,9 \%)$ & $14(20,0 \%)$ & $30(15,2 \%)$ & $6(5,9 \%)$ & $4(12,1 \%)$ & $12(8,3 \%)$ & $19(9,0 \%)$ & $8(3,1 \%)$ & $2(2,4 \%)$ & $101(7,7 \%)$ \\
\hline & very satisfied & $22(10,7 \%)$ & $2(2,9 \%)$ & $1(0,5 \%)$ & $3(3,0 \%)$ & $1(3,0 \%)$ & $6(4,2 \%)$ & $13(6,2 \%)$ & $63(24,1 \%)$ & $6(7,3 \%)$ & $117(9,0 \%)$ \\
\hline & no response & $10(4,9 \%)$ & $4(5,7 \%)$ & $42(21,3 \%)$ & $4(4,0 \%)$ & $0(0,0 \%)$ & $5(3,5 \%)$ & $0(0,0 \%)$ & $0(0,0 \%)$ & $0(0,0 \%)$ & $65(5,0 \%)$ \\
\hline & dissatisfied & $62(30,2 \%)$ & $25(35,7 \%)$ & $46(23,4 \%)$ & $38(37,6 \%)$ & $16(48,5 \%)$ & $25(17,4 \%)$ & $69(32,7 \%)$ & $114(43,7 \%)$ & $16(19,5 \%)$ & $411(31,5 \%)$ \\
\hline$y=3$ & indifferent & $42(20,5 \%)$ & $16(22,9 \%)$ & $37(18,8 \%)$ & $18(17,8 \%)$ & $4(12,1 \%)$ & $53(36,8 \%)$ & $24(11,4 \%)$ & $26(10,0 \%)$ & $22(26,8 \%)$ & $242(18,6 \%)$ \\
\hline & satisfied & $49(23,9 \%)$ & $12(17,1 \%)$ & $23(11,7 \%)$ & $26(25,7 \%)$ & $8(24,2 \%)$ & $37(25,7 \%)$ & $22(10,4 \%)$ & $19(7,3 \%)$ & $37(45,1 \%)$ & $233(17,9 \%)$ \\
\hline $\bar{d}$ & very dissatisfied & $37(18,0 \%)$ & $12(17,1 \%)$ & $46(23,4 \%)$ & $12(11,9 \%)$ & $5(15,2 \%)$ & $20(13,9 \%)$ & $90(42,7 \%)$ & $85(32,6 \%)$ & $2(2,4 \%)$ & $309(23,7 \%)$ \\
\hline & very satisfied & $5(2,4 \%)$ & $1(1,4 \%)$ & $3(1,5 \%)$ & $3(3,0 \%)$ & $0(0,0 \%)$ & $4(2,8 \%)$ & $6(2,8 \%)$ & $17(6,5 \%)$ & $5(6,1 \%)$ & $44(3,4 \%)$ \\
\hline & Total & $205(100,0 \%)$ & $70(100,0 \%)$ & $197(100,0 \%)$ & $101(100,0 \%)$ & $33(100,0 \%)$ & $144(100,0 \%)$ & $211(100,0 \%)$ & $261(100,0 \%)$ & $82(100,0 \%)$ & $1304(100,0 \%)$ \\
\hline
\end{tabular}




\section{Supplement 7 - Urban form characteristics of the $3 * 3 \mathrm{~km}$ buffer zones of around the 21 case-study schools}

$\begin{array}{cccc}\text { School Name } & \text { Street Connectivity } & \text { Accessibility to } & \text { Population Density } \\ \text { (Inters./ha) } & \text { Public Transport (PT } & \text { Neighborhood } \\ \text { (Inhab./ha) } & \text { Stops/ha) } & \text { Green/Open Spaces }\end{array}$

\begin{tabular}{|c|c|c|c|c|c|}
\hline IT & I.C. "G.Catalano-G. Moscati" & 1.221 & 0.0329 & 3.01 & 0.05 \\
\hline IT & I.C. "Alfieri - Garibaldi" & 1.313 & 0.0266 & 3.01 & 0.0056 \\
\hline IT & I.C. "V. Da Feltre - N. Zingarelli" & 0.63 & 0.0083 & 3.01 & 0.005 \\
\hline $\mathrm{DE}$ & Charles-Dickens-Grundschule & 0.155 & 0.0233 & 16.07 & 0.0133 \\
\hline $\mathrm{DE}$ & Grundschule am Arkonaplatz & 0.391 & 0.0822 & 130.87 & 0.01 \\
\hline $\mathrm{DE}$ & Reinhardswald-Grundschule & 0.247 & 0.0766 & 94.03 & 0.0289 \\
\hline $\mathrm{DE}$ & Grundschule am Traveplatz & 0.422 & 0.0644 & 117.16 & 0.0178 \\
\hline GR & 4th Primary School Ampelokipon & 0.139 & 0.0133 & 14.96 & 0.0044 \\
\hline GR & 18th Primary School Stavroupolis & 0.119 & 0.07 & 3.22 & 0.03 \\
\hline GR & 21st Primary School Thessaloniki & 0.04 & 0.01 & 6.77 & 0.0411 \\
\hline HV & Elementary school Srdoči & 0.69 & 0.04 & 25.55 & 0.005 \\
\hline HV & Elementary school Nikola Tesla & 0.697 & 0.0971 & 27.77 & 0.0171 \\
\hline HV & Elementary school Gornja Vežica & 0.459 & 0.0338 & 263.09 & 0.0085 \\
\hline NL & Prinses margriet & 0.719 & 0.0622 & 97.44 & 0.0111 \\
\hline NL & Arcade and OBS Het Zand & 0.461 & 0.0344 & 33.33 & 0.01 \\
\hline $\mathrm{NL}$ & De Hoge Raven & 0.527 & 0.0444 & 138.85 & 0.0666 \\
\hline $\mathrm{PL}$ & Primary School no 172 & 0.204 & 0.0541 & 24.78 & 0.0023 \\
\hline PL & Primary School no 5 & 0.243 & 0.0125 & 6.83 & 0.0125 \\
\hline TR & Battalgazi Gazi Ortaokulu & 0.739 & 0.0367 & 8.90 & 0.0037 \\
\hline TR & Malatya Atatürk Ortaokulu & 1.094 & 0.0361 & 50 & 0.0253 \\
\hline TR & Doğanşehir Atatürk Ortaokulu & 1.008 & 0.0092 & 12.02 & 0.0184 \\
\hline
\end{tabular}

